FEDERAL RESERVE BANK OF SAN FRANCISCO

WORKING PAPER SERIES

\title{
Mortgage Default and Mortgage Valuation
}

\author{
John Krainer \\ Federal Reserve Bank of San Francisco \\ Stephen F. LeRoy \\ Federal Reserve Bank of San Francisco \\ Munpyung O \\ University of California, Santa Barbara
}

November 2009

Working Paper 2009-20

http://www.frbsf.org/publications/economics/papers/2009/wp09-20bk.pdf

The views in this paper are solely the responsibility of the authors and should not be interpreted as reflecting the views of the Federal Reserve Bank of San Francisco or the Board of Governors of the Federal Reserve System. 


\title{
Mortgage Default and Mortgage Valuation*
}

\author{
John Krainer \\ Stephen F. LeRoy \\ Federal Reserve Bank of San Francisco Federal Reserve Bank of San Francisco \\ Munpyung $\mathrm{O}$ \\ University of California, Santa Barbara
}

November 2, 2009

\begin{abstract}
We develop an equilibrium valuation model that incorporates optimal default to show how mortgage yields and lender recovery rates on defaulted mortgages depend on initial loan-to-value (LTV) ratios. The analysis treats both the frictionless case and the case in which borrowers and lenders incur deadweight costs upon default. The model is calibrated using data on California mortgages. Given reasonable parameter values, the model does a surprisingly good job fitting the risk premium in the data for high LTV mortgages. Thus, from an ex ante perspective, we do not find strong evidence of systematic underpricing of default risk in the run-up to the housing market crisis.
\end{abstract}

\footnotetext{
${ }^{*}$ We are indebted to seminar participants at UCLA, UCSB, the China Economics and Management Academy, the Federal Reserve Banks of Chicago and San Francisco, the Federal Reserve Board, the University of Adelaide, the University of Melbourne and Victoria University (Wellington) for comments. The views expressed are those of the authors and not necessarily those of the Federal Reserve Bank of San Francisco or the Board of Governors of the Federal Reserve System.
} 


\section{Mortgage Default and Mortgage Valuation}

It is generally agreed that lenders and investors dramatically underpredicted mortgage default frequencies in the run-up to the U.S. housing market crisis beginning in 2006. There exist two possible explanations for this failure. The first possibility is that the models of mortgage valuation and default were misspecified, either because they were not parameterized accurately or because they somehow failed to capture the tradeoffs faced by actual participants (borrowers and lenders) in this market. The second possibility is that the models were not flawed, but that the values taken on by exogenous variables that determine defaults lay in the extreme tails of their assumed distributions. In this story, practitioners were simply unlucky; even a forecast generated by an accurate model will be wide of the mark if the shock - in this case, a shock to house prices - is three or four standard deviations from its mean.

We conclude in favor of the second candidate explanation. Our analysis involves formulating a model in which changes in housing services, and therefore also house price changes, are taken to be exogenous and unforecastable by borrowers and lenders. Homeowners finance their house purchases with down payments and a mortgage. Borrowers have the option to default on the mortgage, possibly subject to costs, if house prices drop sufficiently, and they are assumed to exercise this option optimally. Here our analysis, like other papers on mortgage default, follows Merton (1974).

To date, a majority of empirical treatments of mortgage default have focused on reconciling theoretical models of default with observed default behavior (for example, Deng, Quigley, and VanOrder (2000)), and do not directly connect optimal default with mortgage loan pricing. A major contribution of our paper is to make this connection. We do this by assuming that mortgage lending is subject to free entry and exit, implying a zero-profit condition for lenders. This zero-profit condition enables us to determine equilibrium yield spreads as a function of initial loan-to-value ratios and the parameters that characterize house price changes. Because we close the model in this way, we are able to provide a full theoretical implementation of Merton's default analysis in the setting of mortgage markets. 
We first conducted this exercise assuming away default costs. Then we assumed that borrowers, but not lenders, suffer costs upon default, and then vice-versa. Finally, we allowed lenders the opportunity to refinance subject to a prepayment penalty. Mortgage default behavior and pricing turn out to be very different in these cases.

The flexibility implied by the difficulty of calibrating these default and prepayment parameters combined with their strong effect on mortgage pricing variables has implications for how we characterize the link between theory and empirical results. The nuisance-parameter problem rules out formal tests of the validity of the model. However, we can proceed in a more informal fashion. The empirical work generates conclusions about what values for mortgage pricing variables are accurate empirically, so we can calibrate to these values. The question becomes whether parameter values can be found that reproduce reasonable values for these variables.

The second major finding of our paper is that we can in fact find parameter specifications that produce values for mortgage variables similar to what we see in the data. One conclusion that follows from this finding is that there is little evidence that mortgages are mispriced relative to underlying housing prices. This conclusion, of course, depends critically on the maintained assumption that house price changes are unforecastable. Some observers have taken the view that, contrary to this, it was obvious that the house price increases that occurred prior to 2006 would shortly be reversed with high probability, and that lenders should have been aware of this possibility and should have charged much higher risk premia. On this account high-LTV mortgages were in fact drastically mispriced. Evidently this line of reasoning contains a considerable element of hindsight. Our point is that if, contrary to this, one maintains the assumption that housing price changes are unforecastable, mortgage markets do not show major distortions.

As noted, our answer to the question asked in the first paragraph is that the heavy losses market participants have experienced on mortgages did not primarily reflect behavior on the part of market participants that was drastically different from the behavior implied in our model. Rather, the losses were the inevitable consequence of a three- or four-sigma drop in house prices. ${ }^{1}$

\footnotetext{
${ }^{1}$ Gerardi, Lehnert, Sherlund, and Willen (2009) reach a conclusion similar to ours, albeit using a different empirical approach.
} 


\section{Default and Mortgage Valuation}

We study the behavior of borrowers and lenders in a stylized housing market where borrowers must decide how to finance their housing purchases. To render the analysis tractable, we made three simplifying assumptions. First, we assumed that mortgages are perpetuities that have no scheduled payment of principal. Thus, all changes in homeowner equity are due to changes in house prices. Since almost all the early payments on 30-year mortgages consist of interest rather than principal repayment, this specification does not involve a major distortion. Second, we assumed that the borrower can always terminate the mortgage by paying the lender its fair market value, even when that value is less than book value (as will occur when house prices drop). As we will discuss below, this specification eliminates the possibility of optimal defaults triggered by adverse life events that affect the borrower's ability to repay the mortgage. Finally, we assumed that interest rates are deterministic. This simplification reflects our focus in this paper on credit risk: specifically, on the difference in mortgage rates induced by existence of the default option for loans with different loan-to-value ratios (LTVs).

We also considered the effect of giving the borrower the option to prepay the loan at its book value subject to a prepayment penalty. Existence of this option affects mortgage pricing even though we abstracted away from the interest rate fluctuations that are usually taken as the major reason for prepayment. In our model prepayment occurs because increases in house values decrease the value of the default option, implying that borrowers whose homes have appreciated are overpaying for the default option. Borrowers are motivated to reduce their payment for the default option to its economic value by refinancing. Like Downing, Stanton, and Wallace (2005), we found that the existence of the default option affects the value of the prepayment option, and vice versa.

We took house prices to be exogenous, thereby shutting down any link between mortgage underwriting practices and house prices. This is a shortcoming, as it is possible that increasingly lax underwriting standards were a contributor to the price run-up that occurred in the decade prior to 2006 (see Coleman, LaCour-Little, and Vandell (2008) and Mian and Sufi (2009)). 


\subsection{The Model Setting}

Our model, like all existing structural mortgage valuation models that incorporate default, is based on Merton's classic paper (Merton (1974)), adapted to the housing market. We assume that housing services $x$ follow a geometric Brownian motion:

$$
d x=\alpha x d t+\sigma x d z
$$

where $\alpha$ is the average proportional increase over time in the level of housing services, $\sigma$ is the associated volatility, and $z$ is a standard Brownian motion. As applied to investment property, $x$ can be interpreted as the difference between rental income and costs to the owner of utilities, repairs, and so on.

It is assumed that the price of housing equals the expectation of future housing services discounted at rate $\rho$ :

$$
P(x(t))=\int_{\tau=t}^{\infty} e^{-\rho(\tau-t)} \mathcal{E}_{t}(x(\tau)) d \tau=\frac{x(t)}{\rho-\alpha} .
$$

Here $\mathcal{E}_{t}$ is the conditional expectations operator. This specification implies that house prices are a geometric Brownian motion and, hence, house price changes are unforecastable. ${ }^{2}$ As a scale choice, we will set $x(0)$, the value of housing services at the date the mortgage is initiated, equal to 1 henceforth. Thus mortgages are initiated when the price of housing equals $1 /(\rho-\alpha)$. The valuation model (1.2) can be justified either by interpreting the probability measure in eq. (1.1) as the risk-neutral measure or more simply by directly assuming that agents are risk neutral. The latter assumption is acceptable here because we are not interested in the effects of risk aversion on mortgage valuation. As noted, mortgages are assumed to be perpetuities (conditional on nonoccurrence of default), and to be indexed by the level of the periodic payment $c$, which we take as exogenous.

The cash supplied by the lender toward the purchase equals the expected present value of the

\footnotetext{
${ }^{2}$ This assumption for the house price process rules out bubbles, and is standard in the mortgage pricing and default literature. See Deng, Quigley, and VanOrder (2000), Downing, Stanton, and Wallace (2005), and Kau and Keenan (1995).
} 
mortgage payments, making appropriate allowance for default as described below. Thus low (high) LTV mortgages can be generated by setting $c$ at a low (high) level. The borrower is assumed to supply the remainder of the purchase price as a down payment.

We will see that, depending on the evolution of $x$, the fair values of mortgages may fall short of their book values or exceed them. In the latter case borrowers are motivated to pay off the mortgages. For the present it is assumed that they cannot do so.

\subsection{Costless Default}

As noted, it is assumed in this subsection that default is costless to both the borrower and the lender. Thus the borrower is assumed to be able to terminate the mortgage at any time by turning over the house to the lender. He incurs no costs due, for example, to reduced access to credit or moving costs. Correspondingly, the lender suffers no loss of value when taking over a foreclosed property.

Borrowers choose the default rule that maximizes the value of their home equity, $E(x)$, or, equivalently, minimizes the value of their mortgage liability, $M(x)$. Using dynamic programming it can be shown that maximizing the value of equity implies that $E(x)$ satisfies the stochastic differential equation

$$
\rho E(x) d t=\mathcal{E}_{x}[d E(x)]+(x-c) d t
$$

where $d t$ is the increment in time and $\mathcal{E}_{x}$ denotes conditional expectation. Thus the discounted gain on $E(x)$ is a martingale, as implied by absence of arbitrage. Here $x-c$ is the analogue of dividends in a stock valuation expression, except that $x-c$ can be either positive or negative, and $d E(x)$ is the capital gain. Using Ito's lemma, (1.3) leads to the (deterministic) differential equation

$$
\frac{1}{2} x^{2} \sigma^{2} E^{\prime \prime}(x)+\alpha x E^{\prime}(x)-\rho E(x)=-x+c .
$$

This differential equation is similar to those arising in finance and also in the real options literature (see Dixit and Pindyck (1994), Ch. 7 for detailed and very clear exposition of a model that contains 
the model here as a special case). The boundary conditions are the value-matching condition

$$
E\left(x_{*}\right)=0
$$

and the smooth pasting condition

$$
E^{\prime}\left(x_{*}\right)=0
$$

The smooth pasting condition is a necessary condition for optimal exercise of the default option since default is a free boundary. It requires that $M(x)$ be tangent to $x /(\rho-\alpha)$ at $x_{*}$.

The value of the mortgage equals the value of the house less the borrower's equity. Thus the value-matching condition implies that the value of the mortgage at $x_{*}$ equals the value of the house, $x_{*} /(\rho-\alpha)$, and the smooth pasting condition implies that the slope of the mortgage value as a function of $x$ is $1 /(\rho-\alpha)$ at $x=x_{*}$. These boundary conditions allow solution for the constant of integration $e$.

For $x>x_{*}$, the solution to the differential equation is

$$
E(x)=e x^{m}+\frac{x}{\rho-\alpha}-\frac{c}{\rho}
$$

where $e$ is the constant of integration:

$$
e=\frac{1}{m(\alpha-\rho)}\left[\frac{c}{\rho}\left(\frac{m(\rho-\alpha)}{m-1}\right)\right]^{1-m}
$$

and $m$ is the negative root associated with the differential equation (1.4):

$$
m=\frac{-\left(\alpha-\frac{1}{2} \sigma^{2}\right)-\sqrt{\left(\alpha-\frac{1}{2} \sigma^{2}\right)^{2}+2 \sigma^{2} \rho}}{\sigma^{2}}
$$

(the constant of integration associated with the positive root equals zero). ${ }^{3}$

The value of the mortgage is given by

\footnotetext{
${ }^{3}$ For $x<x_{*}, E(x)$ does not follow the solution (1.7) to the differential equation (1.4). The simplest way to see this is to observe that for $x<x_{*}$ immediate default is optimal. That being so, the value of the mortgage equals the value of the house, implying that $E(x)=P(x)-M(x)=0$.
} 


$$
M(x)=P(x)-E(x)=\frac{c}{\rho}-e x^{m},
$$

from

$$
P(x)=\frac{x}{\rho-\alpha}
$$

and eq. (1.7). Because $m$ is negative, when $x$ is high the mortgage value approaches $c / \rho$ asymptotically, agreeing with the value it would have in the absence of default. This makes sense: when $x$ is extremely high, default in the foreseeable future is improbable, so it does not materially affect valuation of the mortgage. However, for values of $x$ that are not high, $M(x)$ depends positively on $x$.

Having calculated $M(x)$, one can compute the initial LTV ratio $M(1) / P(1)$, the initial mortgage yield $c / M(1)$, and the recovery rate $P\left(x_{*}\right) / M(1) .{ }^{4}$

\section{$1.3 \quad$ A Numerical Example}

We now provide a numerical example of the equity values and mortgage values as a function of house services that are implied by this model. Our parametrization assumes that $\rho=7 \%, \alpha=3 \%$, $\sigma=10 \%$, so that the average (real) proportional gain on both the equity and the mortgage is $7 \%$, and the initial price-rent ratio is $1 /(\rho-\alpha)=25$ (real-world price-rent ratios are closer to 10 or 15 than 25, but recall that here we are abstracting away from operating costs such as repairs and utilities expense). The standard deviation of the change in housing services, $\sigma$, is taken to be $10 \%$.

Under these parameter values a security similar to a prime mortgage can be generated by specifying that the mortgage payment $c$ is 1.25 . We term this mortgage the "low-LTV" mortgage. This is the specification used to compute $E(x)$ shown in Figure 1. Even though the initial LTV is $71.1 \%$, default does not occur until the house value drops to $62.5 \%$ of its original value. At that price the recovery rate (ratio of collateral value at the default point to the origination value of the mortgage) is $87.9 \%$. The yield on the mortgage at its origination date, equal to $c / M(1)$, is

\footnotetext{
${ }^{4}$ In the calibration section we will make use of the fact that the recovery rate equals the quotient of the default point and LTV.
} 
Figure 1: Market Value of Homeowner Equity as Function of Housing Services

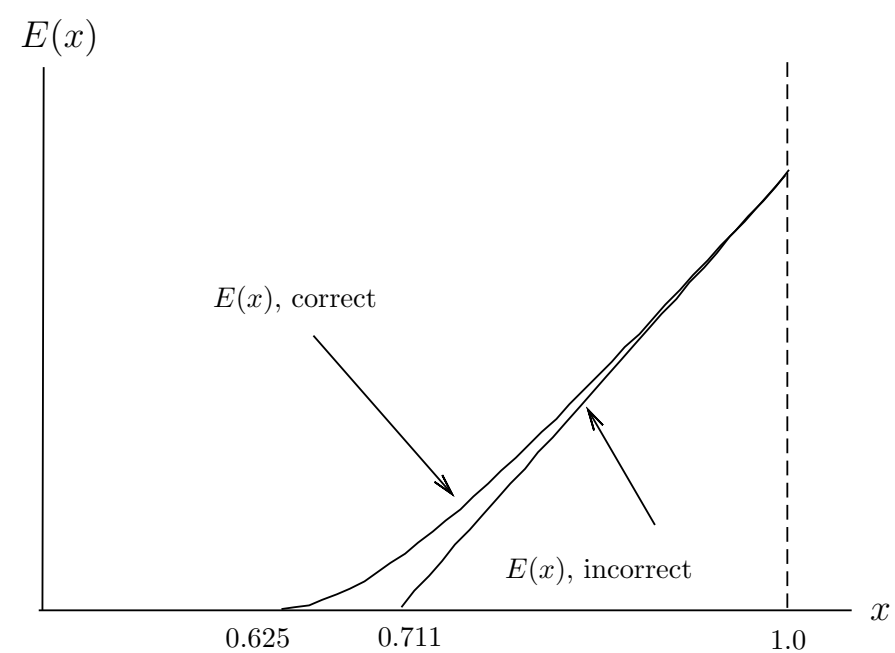

7.03\%. The difference between this rate and the expected return on the mortgage, $7 \%$, represents compensation for the possibility that the collateral value will drop, leading to default.

A high-LTV mortgage results if $c$ is increased from 1.25 to 1.75. This increase in the periodic payment results in an increase in the initiation value of the mortgage; the initial LTV ratio is $95.1 \%$. Default occurs if the house value drops to $87.5 \%$ of its original value. Thus, as would be expected, the magnitude of the price drop that is just sufficient to induce default is much smaller under the high-LTV mortgage than under the low-LTV mortgage. Under the low-LTV mortgage the down payment protects the lender from all but the most drastic price drops, whereas under a high-LTV mortgage the lender has much less protection. Correspondingly, the recovery rate, $92.0 \%$, is higher under the high-LTV mortgage than under the low-LTV mortgage.

The fact that default is likelier under the high-LTV mortgage than under the low-LTV mortgage implies that a higher yield, $7.4 \%$, is needed to compensate the lender for the higher default risk. It is seen that the higher default probability under the high-LTV mortgage relative to the lowLTV mortgage more than outweighs the fact that the recovery rate is higher under the high-LTV mortgage than under the low-LTV mortgage.

The example demonstrates an underappreciated feature of option-based default models: optimal default does not occur until the borrower is substantially "underwater" on the mortgage. The reason 
lies in the distinction between the economic value and the book value of the mortgage. A default calculation based on book value would suggest that borrowers should default when house price falls by the amount of the borrower's equity at the origination date (falls to $71.1 \%$ in this example). This decision rule is also depicted in Figure 1, labeled " $E(x)$, incorrect." To see that this decision rule is not optimal, assume that this locus in fact describes $E(x)$, and that the house price drops to exactly $71.1 \%$ so that $E(71.1 \%)=0$. If prices were to fall below $71.1 \%$, the borrower could default instantly and avoid any further loss. In contrast, if house prices were to rise, then the borrower would instantly have strictly positive home equity. Thus the borrower would strictly prefer not to default, contrary to the implication of the diagram that he is indifferent as to whether or not to default. It follows that $E(71.1 \%)>0$, contrary to the diagram.

For a default point to be optimal, the borrower must be indifferent between defaulting and staying in the mortgage at the default point. In our setup, this condition is met by imposing the smooth pasting condition on the solution along with the value-matching condition, which guarantees that the asset value (the house value) and the mortgage value are not just equal at the default point, but also tangent to each other.

To gain further insight into the characteristics of the model solution, we show how mortgage pricing varies with different specifications of house price volatility. We computed $E(x)$ against $x$ for various values of volatility that bracket $10 \%$. The computed curves are shown in Figure 2. Standard options analysis applies here: the higher the volatility of house price changes, the greater is the value of the default option for given $x$, as reflected in $E(x)$. Also, higher volatilities are associated with lower default points.

To get a different view of the effect of alternative specifications of price volatility on mortgage default and mortgage pricing, we also computed the tradeoff between mortgage yield and LTV for different values of volatility. These tradeoffs were obtained by varying the periodic payment $c$, and are shown in Figure 3. 
Figure 2: Market Value of Homeowner Equity as Function of Housing Services, House Price Volatility

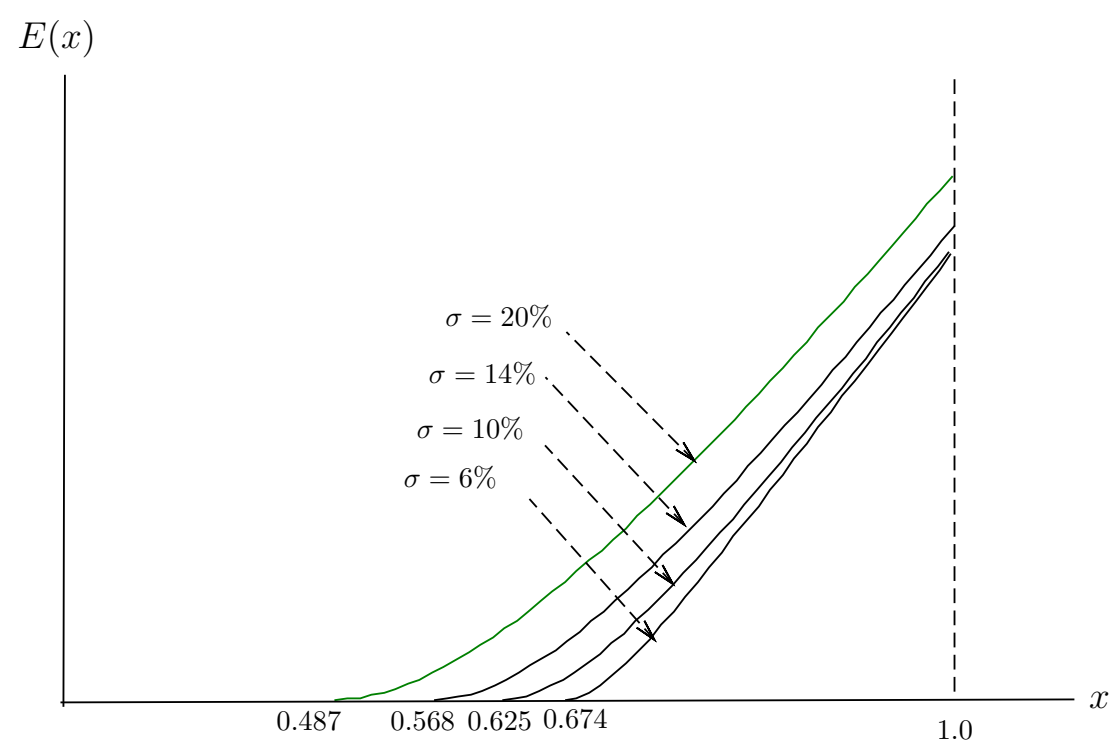

Figure 3: Mortgage Yield as Function of LTV

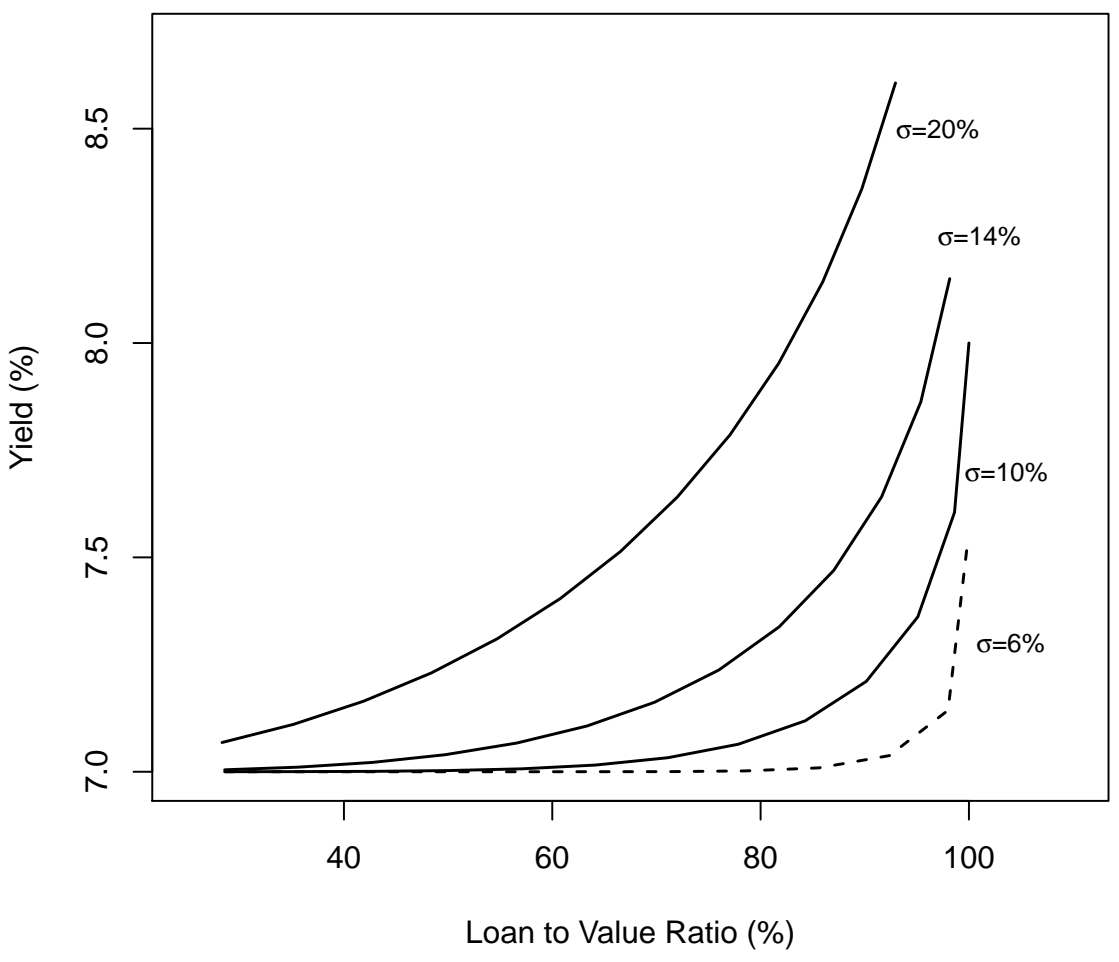




\subsection{Involuntary Default}

The model as specified so far implies that default is always voluntary: agents will default when $x<x_{*}$, and they can and will avoid default when $x>x_{*}$. This conclusion reflects the assumption that when housing services equal $x$ lenders will be willing to accept the market value of the mortgage, $M(x)$, as payment for extinguishing the mortgage. Lenders are willing to do so even though when $x<1, M(x)$ is less than the book value of the mortgage because of the increased risk of default when $x<1$ relative to when $x=1$. Short sales, under which the lender voluntarily accepts repayment of the mortgage at less than its book value, reflect the fact that $M(x)$ is less than the book value of the mortgage when $x<1$. Thus in the model as specified life events such as job loss or medical expenses do not affect optimal default.

Contrary to our model specification, in reality lenders will usually accept mortgage repayment only at full book value (or more, if there exist prepayment penalties) even when full book value exceeds market value. This is so because, first, the borrower cannot credibly threaten to default with high probability if the short sale request is denied. Second, most mortgages are securitized, in which case the servicer often does not have authority to restructure mortgages to avoid default. In any case he almost always lacks incentive to do so. In such cases if the book value of equity is negative the borrower who cannot continue to pay the mortgage may be unable to refinance or sell profitably even when the market value of the equity is positive. In such settings the assertion above that life events like unemployment do not affect mortgage defaults no longer applies.

\subsection{Second-Lien Mortgages}

In practice, borrowers who need a high LTV mortgage often obtain two mortgages: a first-lien mortgage, usually at $80 \%$, and a second-lien mortgage for the difference, which is typically on the order of $10 \%$ or $15 \%$. The first-lien mortgage is senior to the second-lien mortgage, meaning that in the event of default the recovery is applied to it first. There are two institutional reasons for dividing up the mortgage in this way. First, until recently the government agencies declined to insure high-LTV mortgages, rendering them difficult to securitize. Accordingly, dividing mortgages into two pieces made it possible to securitize the senior mortgage. Second, many lenders insisted 
on mortgage insurance when the LTV exceeded $80 \%$, so dividing the mortgage into two securities allowed borrowers to avoid the insurance expense on the senior security.

The model set forth in this paper can easily accommodate dividing a mortgage into two or more pieces. It is reasonable to assume that the borrower's default point is that implied by the LTV associated with the sum of the values of the two mortgages. The question now is how the decomposition of the recovery into payments to the senior and junior debt-holders affects their pricing. Surprisingly, in plausible cases under the model set out here the existence of a second lien actually reduces default risk for the first lien-holder. In such cases the existence of a second lien would be expected to reduce the equilibrium yield on the first lien.

To see this, recall the "low-LTV" (71.1\%) and "high-LTV" (95.1\%) mortgages discussed above. Assume that the high-LTV mortgage is decomposed into the low-LTV mortgage and a second lien with an initial value of $24.0 \%$ of the purchase price. The default point of the high-LTV mortgage is $x_{*}=87.5$, implying that the division of that mortgage into two securities results in the senior mortgage having a $100 \%$ recovery rate in the event of default. In contrast, in the absence of the second lien, default would occur at $x_{*}=62.5 \%$, implying a partial loss for the first lienholder. Thus existence of the second lien ensures that default is timely (from the point of view of the first lien-holder). As a result the first lien would be priced as if it were free of default risk in the presence of the second lien, but not otherwise.

\section{Costly Default and Prepayment}

\subsection{Costly Borrower Default}

In the model of the preceding section the default option is a device that allows sharing between the owner and the lender of the risk of house price decreases. Without a mortgage the owner obviously bears $100 \%$ of the risk, whereas when a lender supplies part of the purchase price, the fact that the value of the mortgage drops as house value drops implies that the lender provides partial insurance to the borrower against the risk of loss of value. The proportions in which the loss is shared between the borrower and lender depend on the volatility of house price changes and 
the terms of the mortgage. The associated transfer of risk entails no deadweight loss, due to the assumption of zero default costs. Accordingly, high-LTV loans imply no inefficiency.

To the extent that the preceding analysis, including the assumption of zero default costs, applies to the US crisis of the last several years, the interpretation is that mortgage markets exhibited nothing that can be called an institutional failure. Along these lines, the story incorporated in the model just presented is that house values dropped several trillion dollars, but these costs were unaffected by the extent of mortgage default. On this interpretation the use of subprime mortgages did not contribute to the magnitude of the loss, and the losses associated with default were a pure transfer involving no deadweight loss.

There is now general agreement in the literature that it is not possible to explain the empirical patterns of mortgage defaults while maintaining the assumption of costless default (e.g., Deng, Quigley, and VanOrder (2000)). Indeed, it appears that some subprime loans were granted that had negative equity at the date of origination, and this is so under either the book or market definition of equity. Existence of such mortgages is possible only in the presence of costs of default that induce borrowers to continue making payments on the loan even when their equity is negative. In the absence of such costs borrowers would default immediately upon closing a negative-equity mortgage. Lenders, anticipating this, would never grant negative-equity mortgages. Thus, the existence of newly originated mortgage loans with negative economic equity is evidence in favor of positive default costs.

Default costs to the borrower include the expense of moving necessitated by eviction, and also the costs associated with impaired access to credit markets in the future. Costs to the lender include expenses incurred repairing, maintaining and reselling foreclosed properties, and also include foregone income during the period (which may be a year or more) between when the borrower terminates mortgage payments and when the lender can gain possession of the property. ${ }^{5}$

To determine the effects of default costs on pricing and expected default behavior we assume the existence of constants $k_{b}$ and $k_{l}$ that capture the default costs of the borrower and lender,

\footnotetext{
${ }^{5}$ The press has reported many instances when defaulting borrowers stole appliances and vandalized the properties upon vacating foreclosed houses. To forestall such behavior, some lenders have offered payments of several thousand dollars to owners of foreclosed properties who turned them over to lenders in satisfactory condition.
} 
respectively. It is assumed that these costs are not received as revenue by any party (of course, one can model costs paid by the lender and received by the borrower, or vice-versa, by setting $k_{l}$ equal to $-k_{b}$ ). We also assume that default costs are proportional to the initial value of the house at the origination date. We did this so as to be able to carry over the assumption of scale-invariance, which implies that the convention that $x=1$ at the mortgage origination date is a harmless numeraire choice. Default costs are assumed to be the same for all borrowers, implying unrealistically that all mortgages with the same contract terms will default, and at the same time, if any of them does. Similarly, all lenders have the same costs.

As in the absence of default costs, it is assumed that there is free entry into, and exit from, the lending industry. Accordingly, lenders adjust loan terms so as to pass the discounted expected value of default costs on to borrowers.

Existence of costly default implies that it is necessary to distinguish between the value of a mortgage to the borrower as a liability and its value to the lender as an asset. The easiest way to see this is to observe that when $x=x_{*}$ the mortgage has liability value of $x_{*} /(\rho-\alpha)+k_{b}$ to the borrower and asset value of $x_{*} /(\rho-\alpha)-k_{l}$ to the lender. Thus the deadweight loss resulting from default at the time of default equals $k_{b}+k_{l}$. We denote the values of the mortgage to the borrower and the lender as $M_{b}(x)$ and $M_{l}(x)$. For any $x$ we have $M_{b}(x)>M_{l}(x)$; this difference is a decreasing function of $x$ because for high values of $x$ the possibility of default is minor contributor to the value of the loan to either borrower or lender. Both mortgage values converge to $c / \rho$ as $x$ goes to infinity, which equals the value of the mortgage when there is no default. ${ }^{6}$

In this subsection it is assumed that $k_{l}=0$, so that borrowers, but not lenders, may have nonzero default costs.

Incorporating borrowers' default costs into the model presented above is achieved by replacing

\footnotetext{
${ }^{6}$ The presence of deadweight losses due to costly default implies an inconsistency in the formulation of the model. The model specifies that the discounted value at $t$ of expected housing services equals $x_{t} /(\rho-\alpha)$ regardless of whether or not a mortgage is used. This specification makes no allowance for the present value of the loss due to default risk when a mortgage is used. Thus when either $k_{b}$ or $k_{l}$ is greater than zero, house buyers using mortgages would find that houses are overpriced relative to the expected value of subsequent housing services.

One could eliminate the problem just noted by setting the initial price at a level lower than $1 /(\rho-\alpha)$. However, the indicated amount of the decrease depends on the loan-to-value ratio. This is different for different values of $c$, the determination of which we are not modeling, so it is unclear how great a decrease to specify. Thus this respecification does not provide an easy resolution of the problem. We prefer to avoid the major respecifications that would be required to deal with this difficulty.
} 
the value-matching condition (1.5) with

$$
E_{b}\left(x_{*}\right)=-k_{b}
$$

so that borrowers default when their equity equals $-k_{b}$. Here $E_{b}(x)$ (i.e., $P(x)-M_{b}(x)$ ) is the borrower's equity. The smooth pasting condition is $E_{b}^{\prime}\left(x_{*}\right)=0$. The values of the mortgage to the borrower and the lender as a function of $x$ are then calculated by using the boundary conditions as modified to derive the constants of integration of the differential equations representing $M_{b}(x)$ and $M_{l}(x)$.

For each specification of default costs we computed the loci of pairs of LTV ratios and mortgage yields in the presence of default costs (see Figure 4). Whenever default costs are strictly positive there are two loci, one corresponding to the initial value of the loan to the borrower and one corresponding to the initial value of the loan to the lender. In Figure 4 it is assumed that $k_{b}=8$, so that $k_{b}$ equals $32 \%$ of the assumed purchase price of 25 . For comparison we also show the corresponding locus when default costs are zero. As above, we assumed $\sigma=10 \%$.

Figure 4 illustrates the consequences of the fact that default is less probable when it is costly to the borrower than when it is costless: for any LTV ratio the equilibrium mortgage yield is lower in the presence of default costs than in their absence. As would be expected, this effect is more pronounced for high-LTV mortgages.

In the presence of borrower's costs as just specified the maximum coupon is $c=2.82$, so that the mortgage payment is almost three times the initial service yield of the house. Accordingly, the value of the mortgage as a liability to the borrower equals $132 \%$ of the value of the house. At that value of $c$ the lender would supply $100 \%$ of the value of the house. The borrower would default virtually immediately (with probability 1), incurring default costs equal by assumption to $32 \%$ of the value of the house.

Now consider lower values of $c$. In that case the borrower would not default immediately. Since the lender would receive high payments for some strictly positive interval of time, he would be willing to supply more cash than when $c=2.82$. This explains the backward-bending LTV-yield locus based on the lender's mortgage value (indicated in Figure 4). 
Figure 4: Mortgage Yield as Function of LTV, Borrower Default Costs

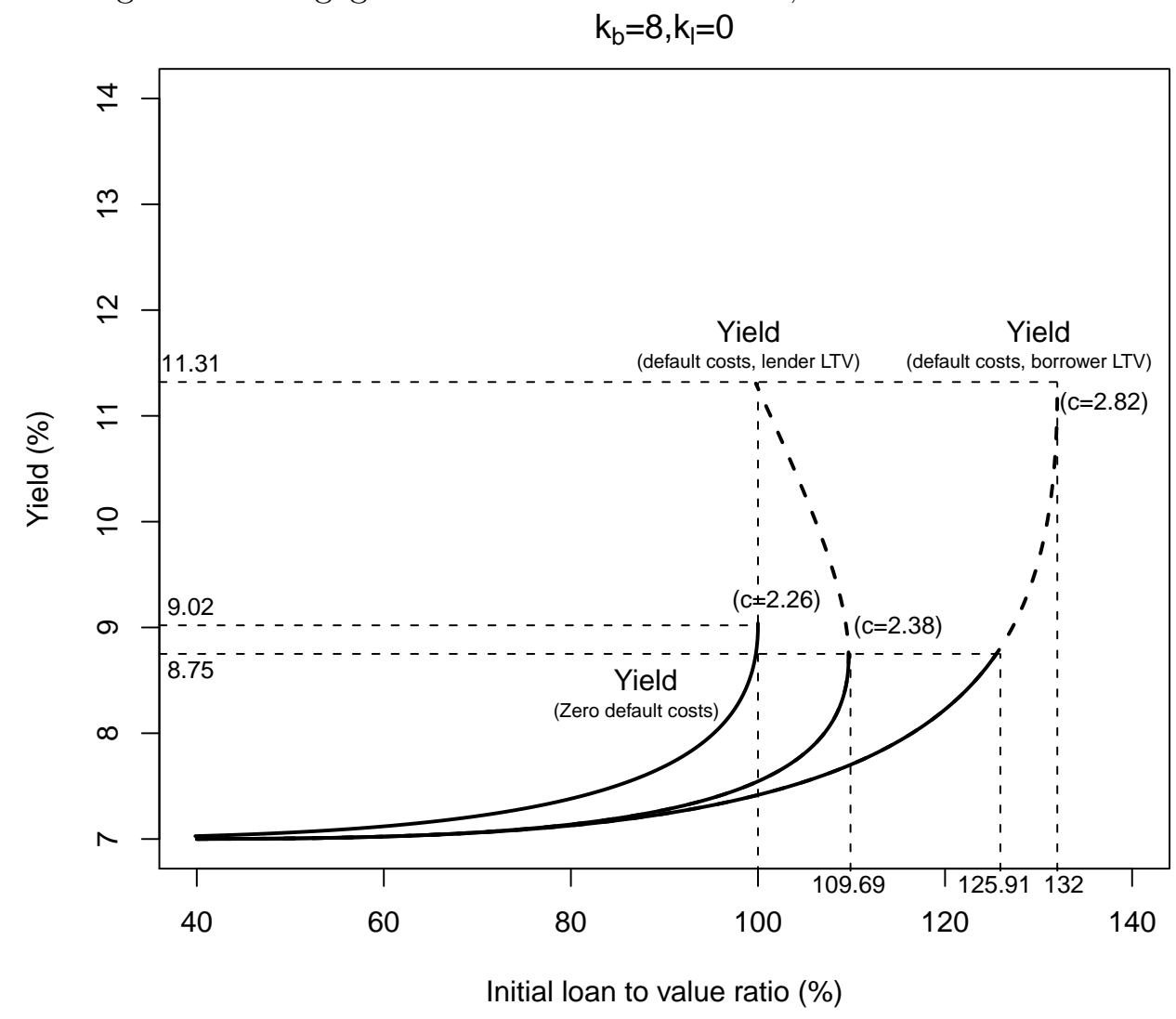


We would not expect to see values of $c$ between 2.38 and 2.82 in equilibrium. For these high values of $c$ lenders would be willing to supply more cash if at the same time they decreased the coupon, so as to decrease the probability of default. Borrowers would insist that they do so. The maximum mortgage payment that is not dominated in this way is that which maximizes the lender's LTV. As the diagram indicates, this is $c=2.38$. At this coupon the lender supplies $110 \%$ of the value of the house, and the liability value of the mortgage to the borrower is $126 \%$. This value of $c$ produces a yield of $8.75 \%$. For successively lower coupons the lender is willing to supply lower amounts of cash, and mortgages are priced to generate yields less than $8.75 \%$.

\subsection{Costly Lender Default}

In this section we set the borrower's default cost $k_{b}$ equal to zero and set the lender's default cost $k_{l}$ equal to 8 . Assuming fixed $c$, nonzero $k_{l}$ does not affect the default point relative to the case in which $k_{l}=0$; the borrower has no incentive to take any account of the seller's default costs. Figure 5 shows that for any yield the lender will supply less cash in the presence of default costs compared to the zero default cost case, for the obvious reason that the mortgage is costlier to him in the event of default. Thus for fixed $c$, high $k_{l}$ implies low initial LTV.

With lenders' default costs the maximal mortgage payment is 2.26 , at which point default is immediate with probability 1 . The existence of a $32 \%$ default cost implies that the lender would supply $68 \%$ of the purchase price.

As with borrowers' costs, the lenders' LTV-yield locus is backward-bending, and the upper portion is dominated. The maximal value of $c$ that is not dominated is $c=1.83$, at which value

the lender will supply $78 \%$ of the value of the house. At this value of $c$ the yield on the mortgage is $9.40 \%$ and the value of the mortgage as a liability to the borrower is $93 \%$.

\subsection{Costly Prepayment}

Up to now it has been assumed that mortgages are terminated only by default, so that, conditional on no default, mortgages are perpetuities. This is obviously a simplification: borrowers have the option to prepay mortgages at their book values, possibly subject to a prepayment penalty. In the 
Figure 5: Mortgage Yield as Function of LTV, Lender Default Costs

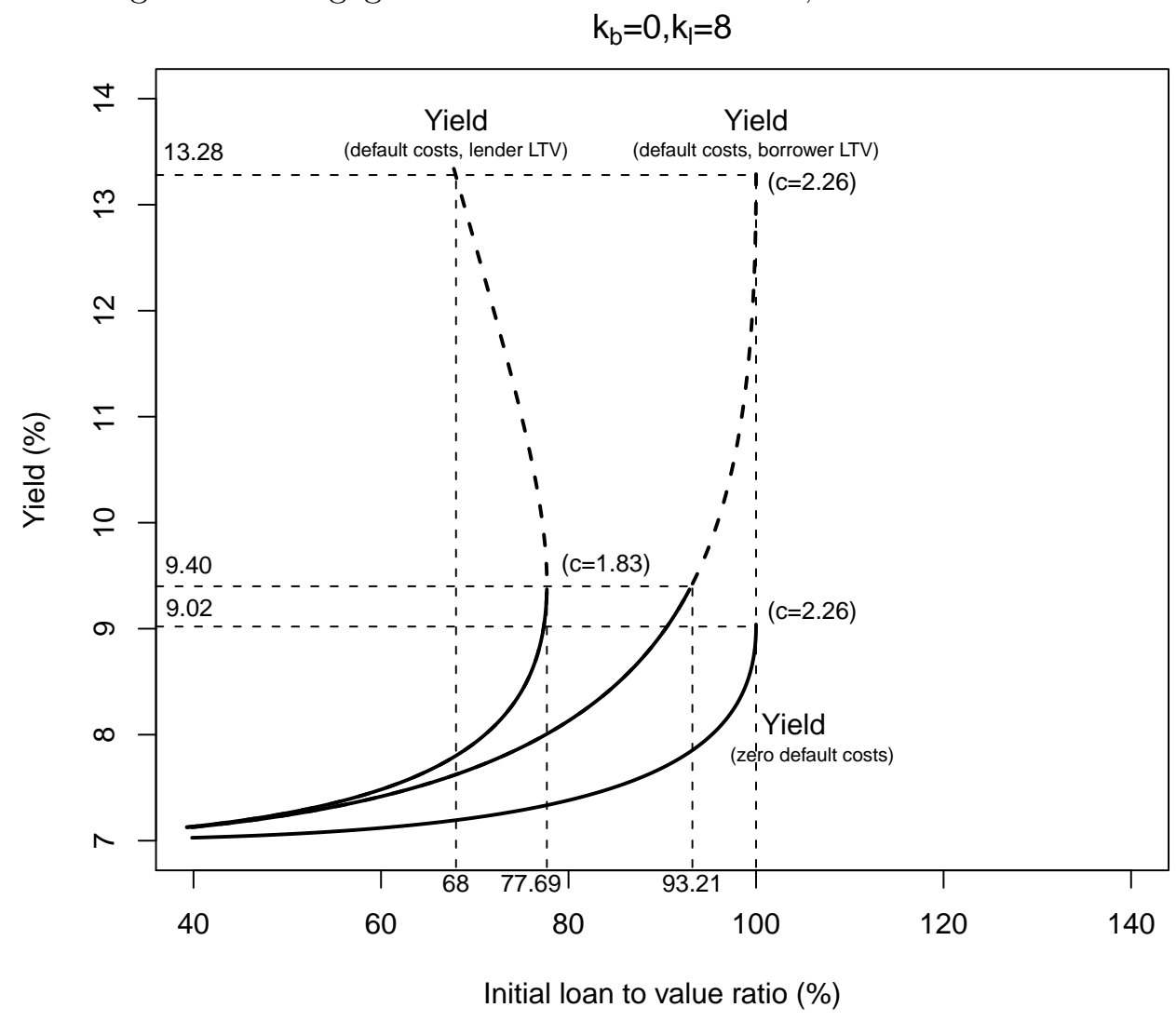


real world they elect to prepay and refinance when prevailing interest rates drop, since otherwise the present value of the mortgage payments would exceed the mortgage's book value. Under the present model this feature is absent since we are taking interest rates to be deterministic and constant.

As noted in the introduction, in the present model increases in house prices generate a motive for prepayment even when interest rates are deterministic. This is so because mortgage values increase with $x$ due to the decreased probability of default in the economically relevant future. For $x>1$ borrowers are paying a higher price for default risk than is justified actuarially, since mortgage payments are based on the default probability appropriate at the origination date, when $x=1$. This, of course, is the reason we have $M(x)>M(1)$ for $x>1$. Thus borrowers have an incentive to prepay their mortgages when the value of the collateral rises above $1 /(\rho-\alpha)$.

The model predicts that borrowers will be willing to make high periodic payments on high-LTV prepayable mortgages because they expect to be able to refinance on better terms after generating additional equity due to capital gains. Further, they are protected from large losses due to decreases in property values because of the default option and the low level of their equity. Thus lenders are subjected to default losses if house values drop, but, due to prepayment, are unable to benefit from large gains if they occur. We therefore expect that lenders will require high periodic payments for high LTV mortgages that are prepayable, particularly if (1) borrowers' default costs are low, so that they will default at high values of $x,(2)$ lenders' default costs are high, and (3) prepayment penalties are low. For the same reasons, borrowers will accept such terms. As emphasized in the financial press, in the past several years we have seen exactly the pattern just described.

In the absence of prepayment costs, borrowers would be motivated to prepay continuously whenever $x>1$. To avoid this unrealistic prediction, we assume that prepayment is subject to a penalty $k_{p}$, so that borrowers will prepay only when the values of their mortgages exceed their origination values $M(1)$ by at least $k_{p} \cdot{ }^{7}$ It is assumed that prepayment is subject to penalty $k_{p}$

\footnotetext{
${ }^{7}$ Note that by deleting the subscipt on $M(x)$ we are excluding default costs. There is a conceptual problem in modeling prepayment in the presence of default costs. If the prepayment penalty is less than the deadweight loss due to default costs at $x=1$, then default will occur at $x=1$. To see this, suppose that $k_{p}<M_{b}(1)-M_{l}(1)$. Then by immediately prepaying their mortgages, borrowers can replace the liability $M_{b}(1)$ with the cost $k_{p}+M_{l}(1)$, which by assumption is lower. The bizarre implication that borrowers would prepay a mortgage that they had just incurred reflects the exogenous specification that homeowners borrow despite the deadweight costs of doing so (when $k_{b}$ or $k_{l}$
} 
regardless of when the prepayment occurs. In reality prepayment penalties apply only during the first several years of the mortgage. Our specification has the advantage that it makes possible extension of the stationary setting adopted in earlier sections.

Define $x^{*}$ as the level of $x$ at which borrowers elect to prepay. To derive an upper bound for $k_{p}$, note that if $k_{p}>c / \rho-M(1)$, the amount the borrower would have to prepay exceeds the maximum value of the mortgage. In that case the borrower will never prepay $\left(x^{*}=\infty\right)$. Thus in the absence of prepayment costs we have $1<x^{*}<\infty$ only when $0<k_{p}<c / \rho-M(1)$. We assume that these inequalities are satisfied.

As shown above, the differential equation defining $E(x)$ has the solution

$$
E(x)=e_{1} x^{m_{1}}+e_{2} x^{m_{2}}+\frac{x}{\rho-\alpha}-\frac{c}{\rho} .
$$

Here, as opposed to the derivation of $E(x)$ when no prepayment was allowed, both constants of integration $e_{1}$ and $e_{2}$ are nonzero. The roots $m_{1}$ and $m_{2}$ are given by

$$
m_{1}, m_{2}=\frac{-\left(\alpha-\frac{1}{2} \sigma^{2}\right) \pm \sqrt{\left(\alpha-\frac{1}{2} \sigma^{2}\right)^{2}+2 \sigma^{2} \rho}}{\sigma^{2}} .
$$

The boundary conditions are the value-matching conditions

$$
E\left(x_{*}\right)=0
$$

and

$$
E\left(x^{*}\right)=\frac{x^{*}-1}{\rho-\alpha}+E(1)-k_{p}
$$

The smooth pasting conditions are

$$
E^{\prime}\left(x_{*}\right)=0 \text { and } E^{\prime}\left(x^{*}\right)=\frac{1}{\rho-\alpha} .
$$

exceeds zero), but are free to terminate the loan at any time upon payment of the penalty $k_{p}$ (see the discussion in footnote 6 . To ensure that refinancing occurs only when $x$ is strictly higher than 1 it is sufficient to restrict attention to values of $k_{p}$ that exceed $M_{b}(1)-M_{l}(1)$.

We sidestep this problem by allowing borrowers to have a prepayment option only when there are no default costs. 
Define $x_{* *}$ as the default point when there is a prepayment option. Then lower values of $k_{p}$ induce lower values of both $x^{*}$, and $x_{* *}$. To see this, suppose initially that $k_{l}$ is very high, so that that there is no prepayment. In that case the borrower is indifferent between defaulting and continuing to pay the mortgage when $x=x_{*}$. Now decrease $k_{p}$ to allow prepayment. Existence of the prepayment option increases the equity of the homeowner for each $x$, implying that $E\left(x_{*}\right)>0$. It follows that $x_{* *}<x_{*}$.

Figure 6 shows mortgage yield as a function of LTV under $\sigma=15 \%$ and $c=1.5$, assuming several prepayment regimes. The solid line shows mortgage values in the absence of a prepayment option. This specification yields the lowest mortgage yield for each value of LTV, as would be expected because then the lender benefits from the decreasing default risk as $x$ increases. The other extreme, generated by $k_{p}=0.1$ and indicated by the dotted line, produces a high yield for each LTV. This is so because the borrower will refinance after experiencing a minor capital gain, so the lender has only a small upside. The cases $k_{p}=0.5$ and $k_{p}=0.25$ are intermediate.

As Downing, Stanton, and Wallace (2005) observed, the prepayment option interacts with the default option. Most obviously, in the present model borrowers would have no motive to prepay in the absence of the default option. Conversely, the optimal default point depends on the prepayment regime: the cheaper prepayment is, the lower the optimal default point. Figure 7 shows the dependence of the optimal default point on the prepayment penalty. 
Figure 6: Mortgage Yield as Function of LTV, Prepayment

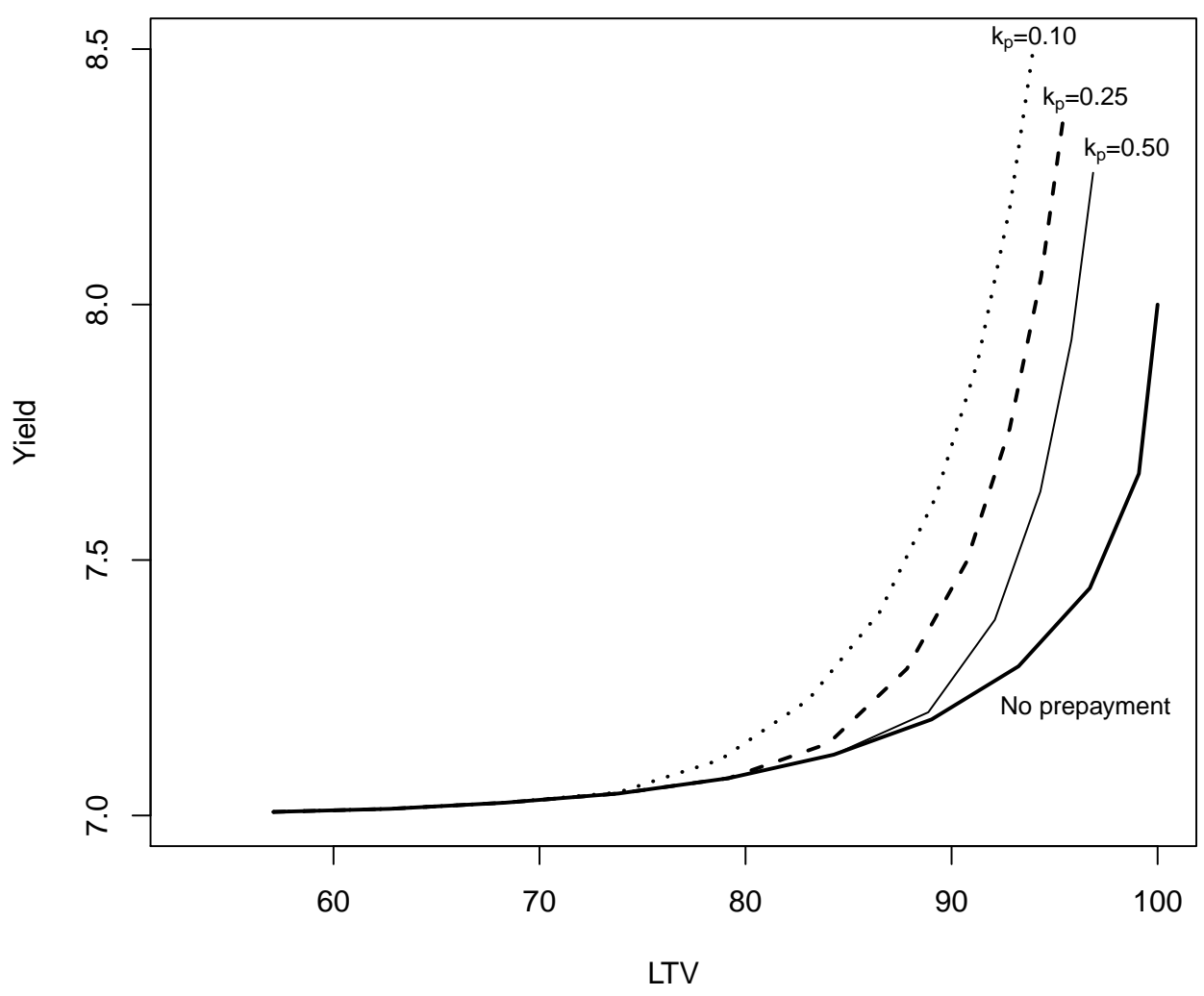


Figure 7: Mortgage Value with and without Prepayment Penalty

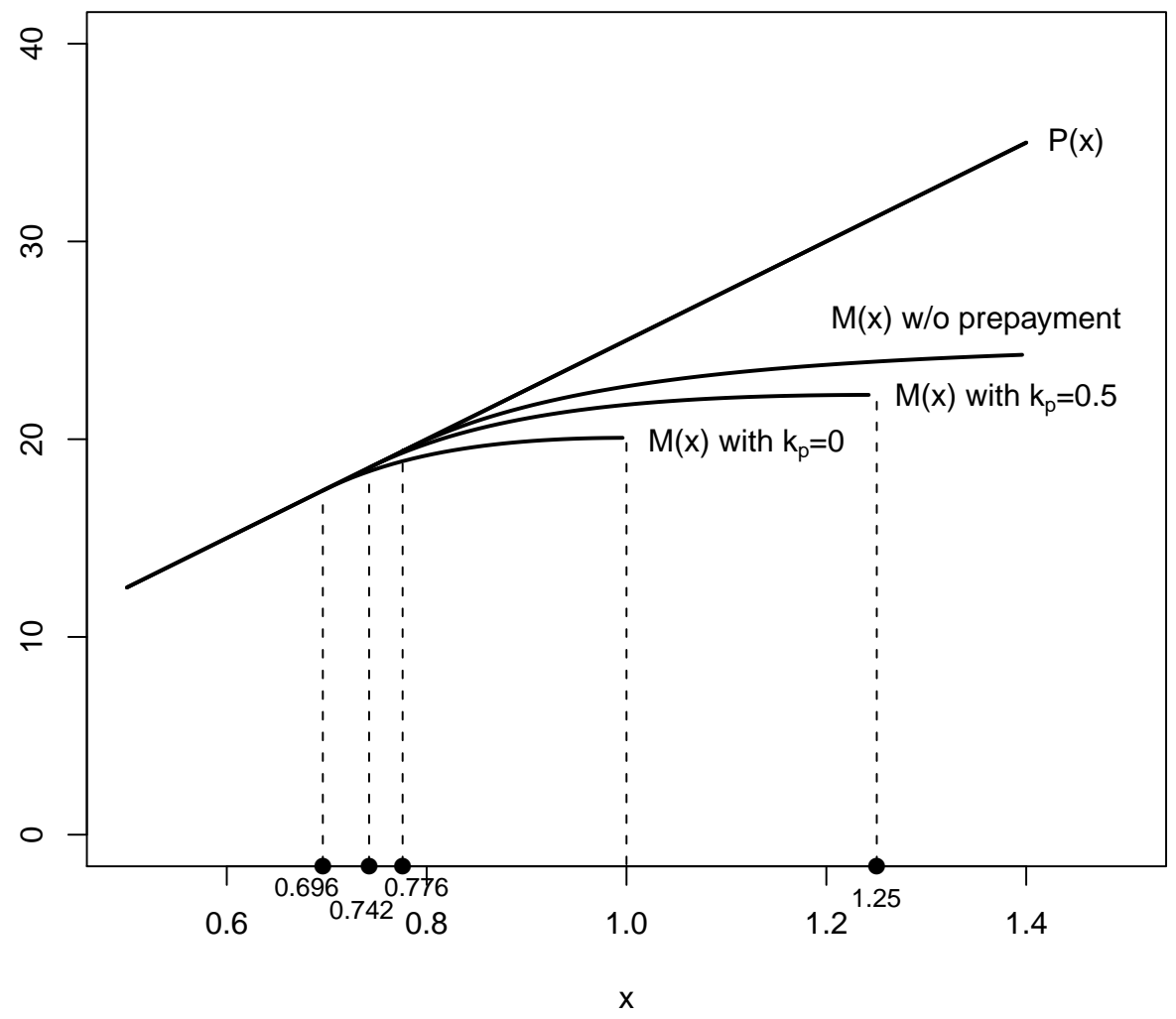




\section{Implementation of the Model}

\subsection{Data}

We used data provided by LPS Applied Analytics. LPS collects loan-level data on mortgage characteristics and performance from nine of the top ten US mortgage servicers, accounting for about 60 percent of the entire U.S. mortgage market. The overall historical data set contains about 107 million loans, with about 33 million active loans as of the end of 2008 .

In order to reduce the data set to a more manageable size we restricted attention to loans made on properties in California. Our sample contains loans originated between 2000 and 2007. We limited our attention to conventional loans originated for home purchases. We adopted this restriction because refinancing decisions are governed largely (but not entirely, as discussed above) by interest rate changes, which are suppressed in the model presented here. ${ }^{8}$

Table 1: Summary statistics

\begin{tabular}{|c|c|c|c|c|c|c|}
\hline & Full sample & & 2002 & & 2006 & \\
\hline & mean & std. dev. & mean & std. dev. & mean & std. dev \\
\hline Origination amount $(\$ 000)$ & 392 & 265 & 290 & 199 & 461 & 291 \\
\hline Term of Loan (months) & 360 & 41 & 348 & 45 & 375 & 47 \\
\hline Loan-to-value & .75 & .14 & .76 & .16 & .76 & .15 \\
\hline Subprime & .05 & & .03 & & .08 & \\
\hline Jumbo & .42 & & .29 & & .43 & \\
\hline Fixed-rate & .45 & & .67 & & .33 & \\
\hline Adjustable-rate & .54 & & .32 & & .66 & \\
\hline Securitized & .82 & & .84 & & .84 & \\
\hline Non-agency securitization & .44 & & .27 & & .57 & \\
\hline FICO at origination & 724 & 54 & 725 & 55 & 720 & 55 \\
\hline Fixed-rate spread over $10 y r$ Treasury & $1.78 \%$ & $.52 \%$ & $2.02 \%$ & $.43 \%$ & $1.63 \%$ & $.48 \%$ \\
\hline ARM margin over benchmark & $2.84 \%$ & $1.24 \%$ & $2.54 \%$ & $.61 \%$ & $3.19 \%$ & $1.53 \%$ \\
\hline Observations & 993,943 & & & & & \\
\hline
\end{tabular}

Even with these restrictions, the sample consists of nearly 1 million mortgages. Summary data for the sample are shown in Table 1 . The mean loan amount was $\$ 360,000$ and the mean loan

\footnotetext{
${ }^{8}$ Gerardi, Shapiro, and Willen (2008) called attention to the tendency for borrowers to extract equity and thereby alter their leverage through a cash-out refinance. We abstract from this phenomenon, as borrowers in our model face no credit constraints.
} 
term is 30 years. About 5 percent of the loans were labeled by the originator as being subprime. ${ }^{9}$ About 42 percent of the loans are nonconforming jumbo loans, a much higher figure than would obtain nationally. This statistic represents the fact that California housing prices are higher than those in other parts of the country, implying that a larger proportion of California loans exceed the upper bound for conforming loan amounts than is true nationwide. A full 84 percent of the loans were securitized. More than half of the securitized loans were nonagency, or private-label, securitizations.

Many of the variables in Table 1 are interpreted naturally as default risk factors. As such, they do not enter directly into the formal model developed above: in the model borrowers are treated as homogeneous and are assumed to be able to refinance whenever the market value of equity is positive. As noted, these assumptions are unrealistic empirically. As a result of borrowers' inability to prepay mortgages at market values when these values have dropped due to housing price decreases, one would expect default rates to reflect borrowers' risk factors as well as house price changes. Accordingly, risk factors such as the credit score and other variables speaking to ability to repay mortgages would be expected to influence default behavior and mortgage rates.

The credit score (i.e., the FICO score) is the main demographic control used in the empirical analysis. The mean FICO score in the sample is 724, which would generally indicate a prime borrower. Despite the fact that the theory presented above deals only with fixed-rate mortgages (FRMs), we will frequently make comparisons between FRMs and adjustable-rate mortgages (ARMs). We do this because it turns out that these two classes of mortgages have different default behavior as well as pricing characteristics.

The fact that our formal model does not incorporate borrower risk variables would not be a major concern if these risk variables were uncorrelated with LTV ratios. However, this uncorrelatedness property is not satisfied in the data. Table 2 shows a correlation matrix between LTV ratios and several risk variables. As expected, high LTV ratios are associated with risky borrowers; that is, borrowers with low FICO scores. Borrowers with high LTVs are more likely to have an ARM

\footnotetext{
${ }^{9}$ Mayer, Pence, and Sherlund (2008) reported that subprime loan originations increased from about $10 \%$ of total mortgage originations nationwide in the early 2000 s to a peak of $35 \%$ of total originations. Thus, subprime loans appear to be underrepresented in the LPS data.
} 
than a FRM. To deal with these associations we will include controls for borrower risk in many of the tabulations.

Table 2: Correlation matrix for risk factors

\begin{tabular}{lcccc} 
& LTV & FICO & ARM & Jumbo \\
LTV & 1 & & & \\
FICO & -.24 & 1 & & \\
ARM & .12 & -.12 & 1 & \\
Jumbo & .05 & .09 & .34 & 1 \\
\hline
\end{tabular}

Table 1 also displays summary statistics for mortgages originated in two years, 2002 and 2006. Since 2002 followed a recession and 2006 coincided with the peak of the housing boom, comparison of these two years provides a useful summary of mortgage market changes over time. First, note that the run-up of housing prices in the first half of the current decade coincided with a sharp increase in average loan size: from $\$ 290,000$ in 2002 to $\$ 461,000$ in 2006 . One would expect that average LTVs would drop over the period since individuals changing homes in 2006 could carry over major capital gains, which was much less true in 2002. However, there was no change in average LTV ratios, pointing to the fact that individuals were apparently using debt to finance higher levels of consumption than would otherwise be possible. It is important to remember that the LTV ratios used here are computed from the first lien mortgage. As we discuss below, true leverage was surely higher in aggregate than what is reported in Table 1.

The proportion of the sample labeled subprime almost tripled, from $3 \%$ to $8 \%$, between 2002 and 2006. The proportion of loans that exceeded conforming loan limits set by the GSEs (the jumbo share) increased from 29 per cent to 43 per cent. Significantly, in 2002 about two-thirds of the loans were FRMs, with the remainder being ARMs, while these ratios were reversed in $2006 .{ }^{10}$ Again, the increase in loan amounts necessitated by rising housing prices led rising numbers of borrowers to use ARMs, for which qualifying is easier. Finally, securitization rates were much higher in 2006 than in 2002 .

Figure 8 shows that average FICO scores were somewhat lower in 2006 than in 2002. That

\footnotetext{
${ }^{10}$ FRMs and ARMs make up about $99 \%$ of the loans in the sample in any given year. Interest-only and optionARMs are classified as adjustable-rate mortgages for these purposes. The remaining $1 \%$ of the sample consists of various alternative mortgages, such as graduated payment mortgages.
} 
Figure 8:

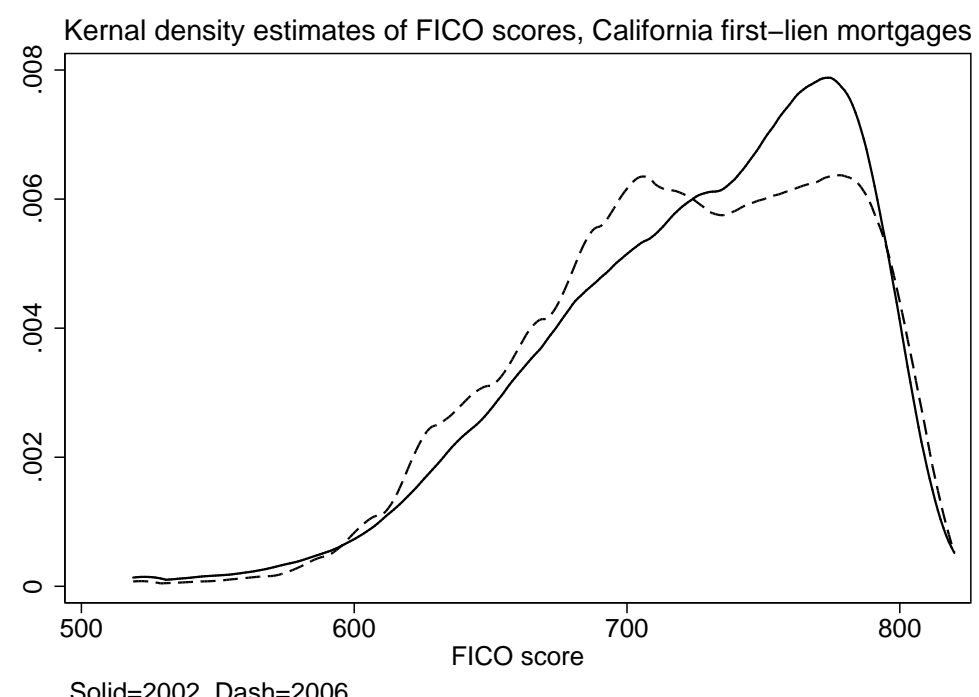

FICO scores dropped at all over this period is surprising: housing prices had risen sharply from 2002 to 2006, implying that most homeowners in financial difficulty could readily refinance or sell in order to avoid defaulting on financial obligations. The fact that FICO scores dropped despite this fact is consistent with other evidence of declining underwriting standards during this period (see Demyanyk and van Hemert (2008)).

\subsection{LTV and Default}

The theoretical model presented above focused on initial LTV and changes in house prices as the major determinants of default. It is not difficult to link house price changes to default behavior in the data. ${ }^{11}$ House prices in California doubled between 2000 and the peak in 2006, and then proceeded to fall by more than $25 \%$ through year-end 2008. In the early part of this period delinquency rates were very low and stable, before starting a dramatic upward surge at about the same time as the peak in house prices. Generally speaking, California housing markets that experienced large price declines were also characterized by high default rates (see Figure 9).

\footnotetext{
${ }^{11}$ See Doms, Furlong, and Krainer (2008), Gerardi, Shapiro, and Willen (2008), and the references therein for a discussion of the house price-default correlation.
} 
Figure 9:

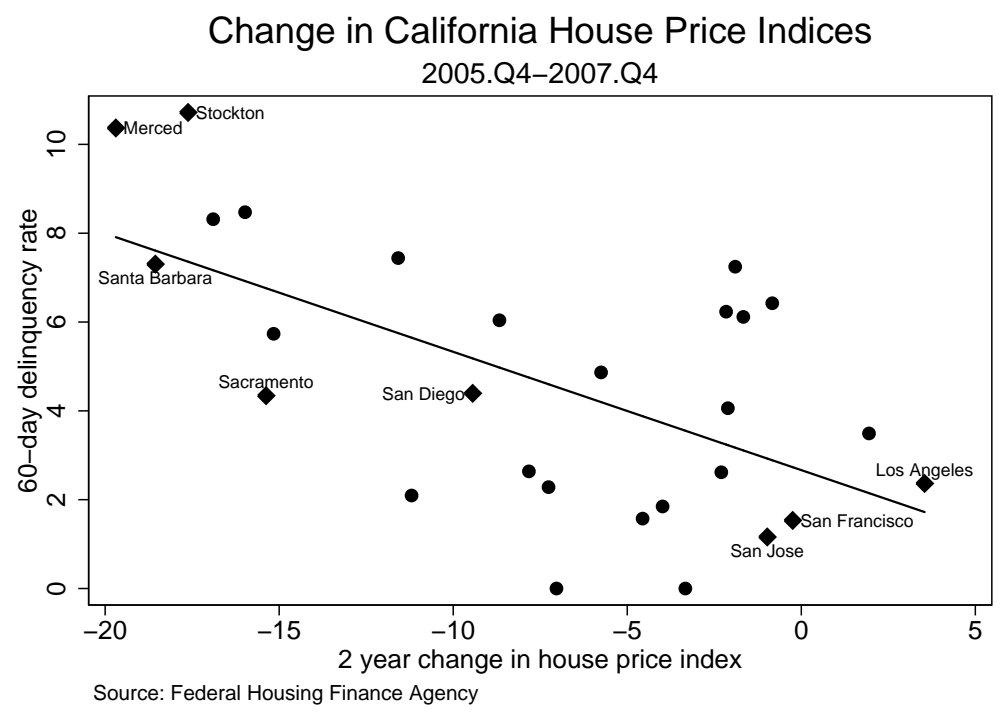

Theory suggests that default rates for borrowers with high LTVs will be more sensitive to house price declines than those for low LTV borrowers. Unfortunately, directly testing this implication of the model is not straightforward. The problem is that, as noted above, high-LTV borrowers frequently combine an $80 \%$ first-lien mortgage with a second lien rather than borrow the full amount using a single mortgage. We have no information about which first-lien mortgages are linked to a second-lien mortgages, but have every suspicion that such linkages exist. To see this, consult Figure 10, which shows the distribution of LTV ratios in 2002 and 2006 for FRMs and ARMs. In 2002 a considerable fraction (22\%) of the first-lien FRMs had LTVs greater than $80 \%$. This fraction diminished to about $6 \%$ in 2006. As Figure 10 suggests, the reshaping of this distribution resulted in a strong concentration of loans with exactly $80 \%$ LTV. Given the sharply rising house prices over this time period that generally outpaced increases in income, the presumption is that a substantial fraction of the $80 \%$ mortgages were associated with second-lien mortgages, raising the combined LTV above the level indicated by the data by an amount that we cannot directly measure.

In our data, the default rate on $80 \%$ LTV mortgages is higher than the default rate for either $79 \%$ or $81 \%$ LTV mortgages. As discussed above, this pattern would be expected if $80 \%$ mortgages 
Figure 10: Kernel density estimates of LTV distribution

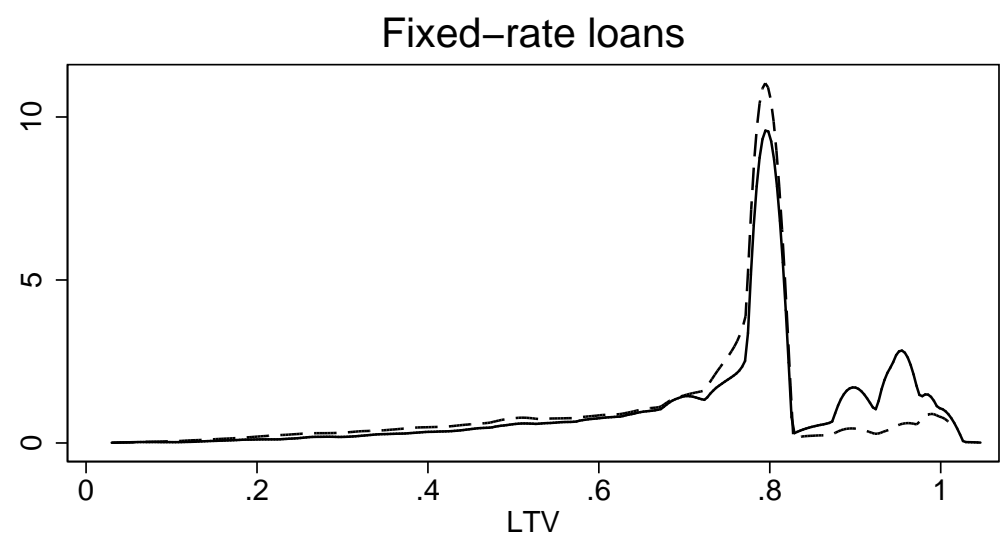

Solid=2002, Dash=2006

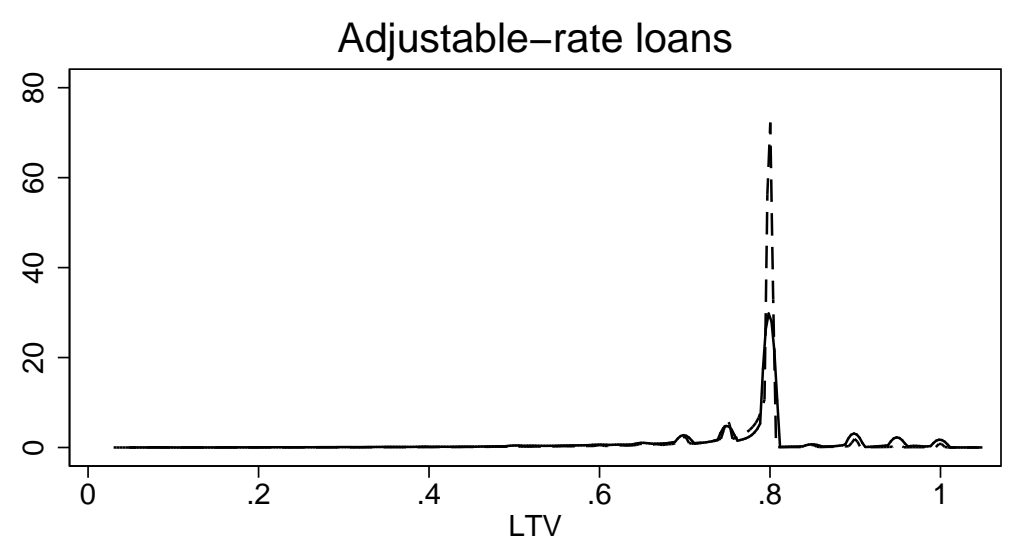

Solid=2002, Dash=2006 
are frequently accompanied by second-lien mortgages, but $70 \%$ and $81 \%$ mortgages are not. Away from $80 \%$, however, we have more confidence that the leverage implied by the first lien on the property is an accurate measure of total leverage.

Figure 11 displays the cumulative default frequencies plotted against the time since origination for loans in our data set. Mindful of the potential problems interpreting the default behavior for $80 \%$ LTV loans, we defined a low LTV mortgage to be one where $.65<L T V<.75$, and a corresponding high LTV mortgage by $.85<L T V<.95$. The high-LTV mortgages default at about twice the rate of low-LTV mortgages. Note that even though the relative rates of default between high and low LTV mortgages are about the same for FRMs and ARMs, the level of the default rate on ARMs is much higher than on FRMs.

Figure 11:

\section{Cumulative Default Rates}

\section{FRMs}

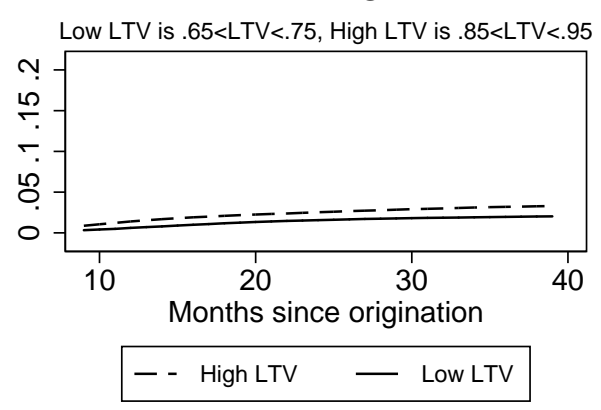

ARMs

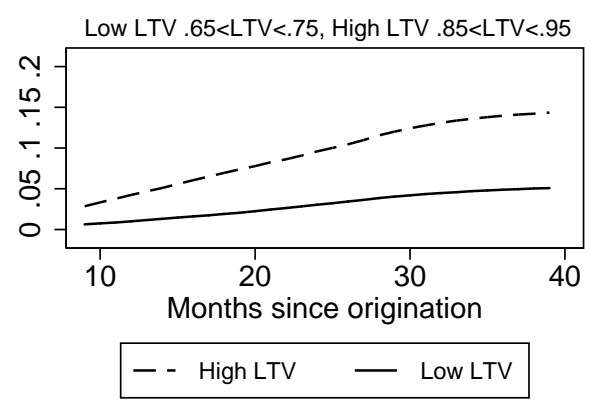

High LTV FRMs

High LTV is . $85<\mathrm{LTV}<.95$, low FICO $<700$, high FICO $>700$

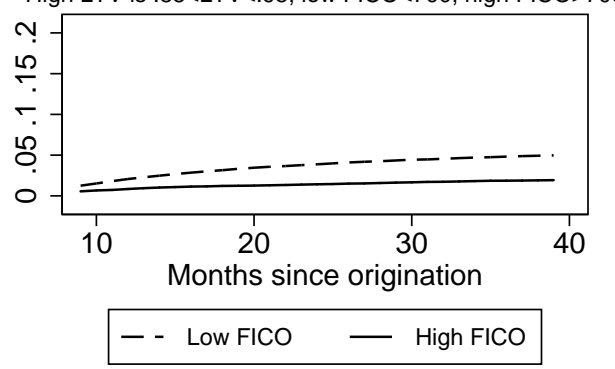

High LTV ARMs

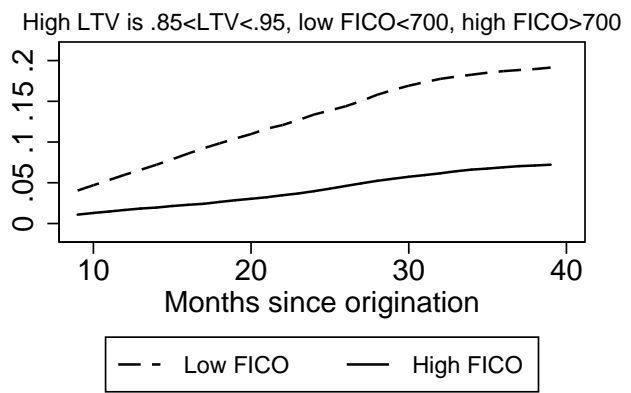

So far all these results, following the theoretical model, ignore borrowers' risk factors. In the 
discussion above we noted that, in reality, borrowers are often unable to repay mortgages at their economic values when these have dropped. Thus, default frequencies would be expected to depend on borrowers' risk variables as well as LTV and house prices. This dependence is seen in the data. The two right-most panels of Figure 11 show the differential performance of high FICO score mortgages compared to low FICO score mortgages. FICO score is negatively correlated with LTV in our data. However, holding LTV constant, we still see that low FICO score borrowers default much more than high FICO score borrowers. For FRMs with $.85<L T V<.95$, the default rate 40 months after origination was about $5 \%$ for borrowers with FICO scores below 700, as compared to $2 \%$ for borrowers with FICO scores above 700 . For ARMs, the corresponding default rates were $20 \%$ and $8 \%$ for high and low FICO score borrowers, respectively.

We can also see the clear effects of differential house price appreciation on the cumulative default rates. For all classes of mortgages - fixed and adjustable - and for all ranges of LTV, the 2002 vintages performed much better than the 2006 vintages (Figure 12). Of course, virtually all mortgage borrowers in the 2006 vintage experienced house price depreciation over the following three years. Even so, it is remarkable to see the disastrous performance of the high LTV ARMs in the 2006 vintage (in Figure 12, note the difference between the vertical scale in the lower right panel and the others). Within 24 months, nearly half of this vintage was in default.

In summary, the data provide clear evidence that LTV is a risk factor: for both FRMs and ARMs, high LTV loans have significantly higher default rates than low LTV loans. This is true both unconditionally and conditional on risk factors.

\subsection{LTV and Mortgage Pricing}

In the theoretical model it was assumed that equilibrium mortgage pricing takes account of default risk. Because initial LTV governs default risk, the model predicts that mortgage spreads (equal to the difference between the coupon rate on mortgages less the risk-free return) depend positively on initial LTV (because the optimal default point is higher for high-LTV mortgages, implying that default is more probable with them).

Our empirical measure of spread differs by mortgage type. For FRMs with loan terms of 15 years 
Figure 12:

\section{Cumulative Default Rates by Vintage}

FRMs

Low LTV is .65<LTV $<.75$

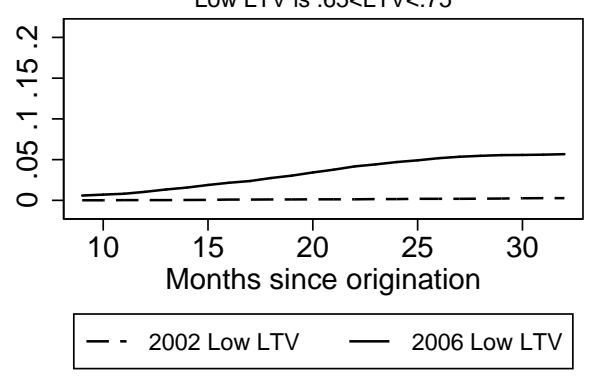

ARMs

Low LTV is . $65<$ LTV $<.75$

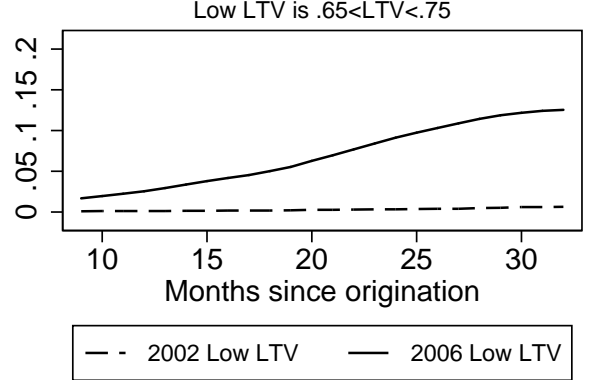

FRMs

High LTV is . $85<L T V<.95$

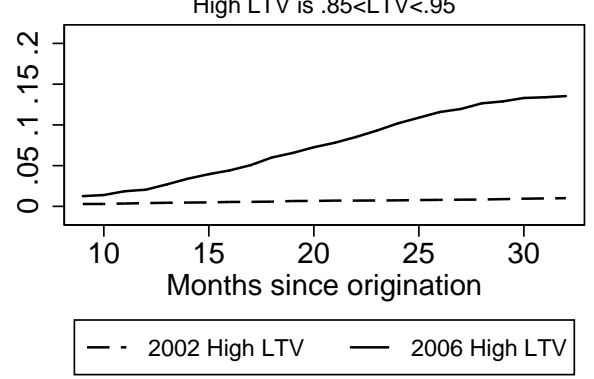

ARMs

High LTV is . $85<L T V<.95$

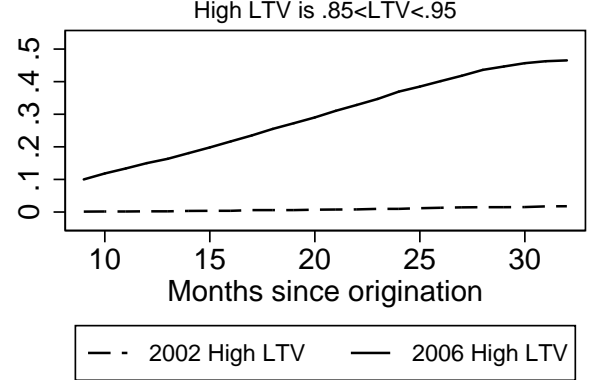


or more we used the difference between the fixed mortgage rate and the average 10-year constant maturity Treasury yield in the 30 days leading up to the date the mortgage was originated. For ARMs we used the so-called "margin rate", which is the difference between the mortgage rate and the benchmark rate to which the ARM is tied. To estimate the spread-LTV relationship, we assume that the spread on mortgage $i$ with LTV $j$ in market $k$ can be modeled as,

$$
s_{i j k}=a_{k}+d_{j}+\theta X_{i}
$$

Here, $a_{k}$ is a market-specific intercept meant to capture possible variation in expectations for future house price behavior and volatility across geographic areas. A local market is defined as a metropolitan statistical area (MSA). All mortgages on properties not located in an MSA are coded as "rural." To capture the relationship between spread and LTV as flexibly as possible, we partition the space of LTV ratios into 5 percentage point intervals (or buckets). The term $d_{j}$ is specific to all loans with $j \%<L T V \leq j+5 \%$ for $j$ ranging from $45 \%$ to $95 \%$. That is, the $45 \%-50 \%$ bucket is the lowest LTV bucket and $95 \%-100 \%$ is the highest bucket. The specification above also allows us to include a vector of risk factors, $X_{i}$. These factors control for sources of risk that were not considered in the theory, but are likely to be priced by lenders and to be correlated with LTV. To this end, we included credit score, the log of loan amount, and indicators for whether the loan is a subprime loan, exceeds the conforming loan limit (i.e, is a jumbo loan), is securitized in a nonagency securitization, has fully documented income, and whether or not it has a prepayment penalty. When considering ARMs, we also included dummy variables for whether the mortgage is interest-only, for whether it is an option ARM, and for the benchmark index that the ARM rate is based on. ${ }^{12}$ In all of the results to be presented, we dropped mortgages that had mortgage insurance.

In our estimation of eq. (3.1), we appended a random disturbance to account for unobserved factors and estimated the model by OLS. We also entered year dummies to capture the behavior of systematic economic factors over time. The main objects of interest are the estimates of the $d_{j}$ terms. These terms are literally the coefficients on a set dummy variables for the LTV buckets

\footnotetext{
${ }^{12}$ In our data, the vast majority of the ARMs are indexed to either the 1-year T-bill or 6-month LIBOR.
} 
where the lowest LTV bucket-45-50\% - is the omitted category. Thus, the coefficient estimate on a particular LTV bucket - say 85-90\% LTV - is the estimate of the excess spread paid to raise the LTV from the $45-50 \%$ range to $85-90 \%$, controlling for the market in which the property is located. Figure 13 shows estimated mortgage spreads against LTV for FRMs and ARMs, separately estimated. The solid line shows coefficients of the LTV dummies without correction for risk factors other than LTV, while the dashed line allows for the risk factors.

For FRMs the inclusion of the risk factors has virtually no effect on the coefficients of the LTV dummies: with or without the risk factors, high LTV mortgages are characterized by spreads that are about 40 basis points higher than for low LTV mortgages. Thus in the data the premium on high-LTV FRM loans does not depend on whether or not one corrects for risk factors. This striking result is contrary to our prior expectation, which was that the spread-LTV locus would be flatter when risk controls were included than when they were not. Of course, the risk factors considered here do have an effect on loan pricing: for example, low credit score borrowers tend to have higher mortgage rates than high credit score borrowers, all else held equal. Our finding is that the risk factors do not interact with LTV.

Turning to ARMs, without correcting for risk factors the estimated difference between spreads on high vs low LTV ARMs is much greater, at about 150 basis points, than that on FRMs. Including the risk factors reduces the differential yield spread to 90 basis points. Thus, whether or not one controls for risk factors, high LTV borrowers with ARMs were perceived by lenders to be much riskier than low LTV borrowers with ARMs. In the previous section we saw that these beliefs were justified in view of the fact that default rates have been much higher for high LTV ARMs than for low LTV ARMs. ${ }^{13}$

We also see that the effect of LTV on yield spreads is much greater when the risk factors are

\footnotetext{
${ }^{13}$ The relationship between spreads and LTV for ARMs is not monotonic. In the figure, the reversal where spreads actually decline as LTV increases comes at $85 \%$ LTV. This appears to be due to a type of market segmentation that is prominent for ARMs, yet much less visible in the FRM data. For ARMs, both the mortgage rate and the credit score change discontinuously around $85 \%$ LTV, with the credit score rising sharply and the rate falling . The fall in the mortgage rate is so abrupt, however, that it is difficult to capture it in the regression framework used here. Admittedly, our sample of first lien ARMs with no mortgage insurance is relatively thin at the highest LTV levels. However, we favor the interpretation that the real-world loan pricing function is sufficiently complex at high levels of LTV, with interactions between LTV and other borrower risk factors becoming increasingly important. What remains unclear, however, is why this complexity should stand out so visibly for the case for ARMs and not FRMs.
} 
Figure 13:

Spreads on FRMs and ARMs as function of LTV

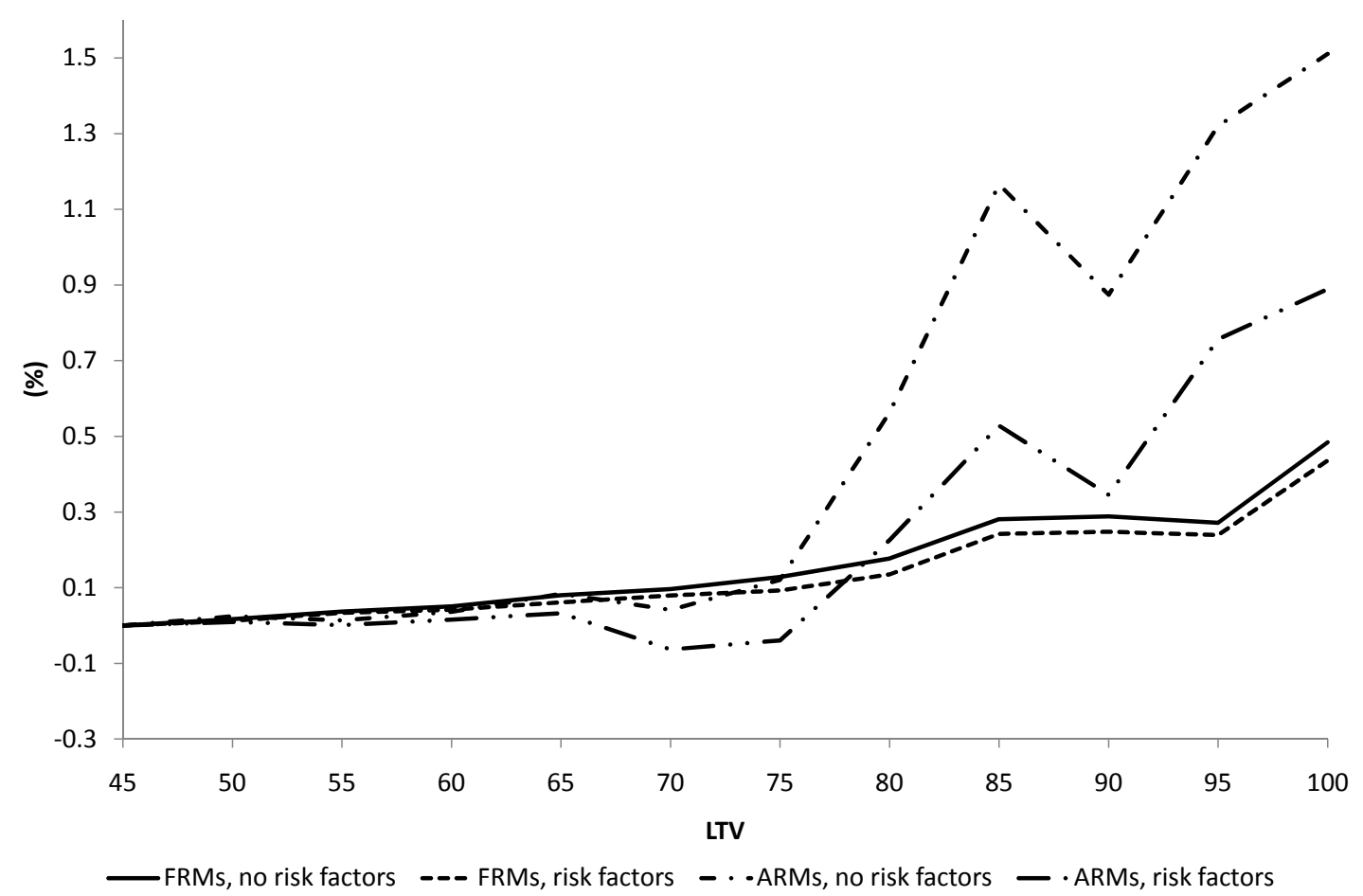


excluded than when they are included. Given the correlation between LTV and risk factors, this is the expected outcome. We have no explanation for why the same result does not obtain for FRMs.

\section{Calibrating the Model}

The final exercise is to attempt a calibration of the model. As in the numerical example discussed above, we set the housing service flow drift at $\alpha=3 \%$ and the rate of time preference equal to $\rho=7 \%$; these values produce empirically realistic values for the real return on housing and mortgages, and a realistic value for the price-rent ratio, as discussed above. With these maintained specifications in place, the key determinants of mortgage rates and expected default behavior in the model will be the volatility of changes in housing services $(\sigma)$ and the assumptions on borrower and lender default costs $\left(k_{b}\right.$ and $\left.k_{l}\right)$.

We will focus on mortgages with LTV around 95\%. Excluding mortgages with LTV equal to $80 \%$ is appropriate because, as discussed above, many of these mortgages are associated with second-lien loans. This difficulty probably does not occur in mortgages with LTV less than $80 \%$, but another problem arises. Mortgages with LTV below $80 \%$ were likely to be eligible for guarantee by Fannie Mae and Freddie Mac. Consequently, whether or not such mortgages were actually sold to Fannie Mae and Freddie Mac upon origination, mortgage lenders have no incentive to incorporate default costs in pricing except insofar as these costs are implicitly reflected in the prices at which the mortgages can be sold. Whether or not this is the case is far from clear. Also, default risk is a minor factor in the pricing of low-LTV mortgages, so in any case such mortgages are of secondary interest given our focus on default and its consequences for mortgage pricing. We are left with mortgages with LTV over 80\%; for concreteness, we focus on mortgages with LTV around $95 \%$.

In view of the fact that we do not have a theoretical model for ARMs, our attention in this section is restricted to FRMs.

We assumed that mortgages are not prepayable $\left(k_{p}=\infty\right)$. Relaxing this assumption and incorporating a prepayment penalty of $k_{p}$ has the same qualitative effect on the spread-LTV plot as imposing strictly positive lender's costs (doing either makes the spread-LTV plot more convex; 
compare Figures 5 and 6). Thus, we proceed under the assumption of costly default and no possibility for prepayment.

Calibrating the model will consist of specifying parameters that generate empirically accurate values of the spread on mortgages with LTV around 95\%, and that generate default behavior that appears to be reasonable. We showed above that empirically the spread for $95 \%$ mortgages is around 30-40 basis points, so we prefer parameter values that generate approximately that value. Reproducing default behavior is more difficult. Ideally, we would back out the default point from the recovery rate and the other parameter values. Our data set contains the recovery rate as a variable, but it is extremely sparsely populated, so this estimator is not open to us. Using actual default rates will not allow a precise calibration because default rates are extremely variable, even among mortgages issued at the same time with equal LTVs. We are reduced to imposing on the data an arbitrary prior specification of default points and recovery rates. We assumed that the recovery rate on a $95 \%$ mortgage is around $60-70 \%$, and calibrate to this value. ${ }^{14}$

We begin by considering the specification of $\sigma$. In the empirical housing literature estimated price volatility is around 15\%. For example, using data from the PSID, Flavin and Yamashita (2002) estimated the standard deviation of the real return on housing to be about $14 \%$. Case and Shiller (1989) report similar estimates for the return on individual houses (14-15\%). ${ }^{15}$ After aggregating individual units to the city or the national level, most house price indices display much less volatility. The annual price change in the Case-Shiller Composite 10 City index has a standard deviation of about $9 \%$ between 1987 and 2008. The annual price change in the FHFA house price index is a little over $3 \%$ over the same time period. Since the loan pricing that we are studying corresponds to rates on individual mortgages, we take the higher estimates of $\sigma$ to be more realistic. We will start by specifying $\sigma=15 \%$, but we will also consider $\sigma=10 \%$.

Table 3 reports computations from the theoretical pricing model that are useful in the calibration

\footnotetext{
${ }^{14}$ If $k_{l}=0$, calibrating from the recovery rate is equivalent to calibrating from the default point (see footnote 4$)$. If $k_{l}>0$, for given default point the recovery rate relevant for the lender will be lower than that resulting from this calculation.

It is worth noting from this that if one had separate priors about the default point and the recovery rate, one could in principle directly calibrate $k_{l}$.

${ }^{15}$ The Flavin and Yamashita and the Case and Shiller estimates of the standard deviation of housing returns are based on data sampled from across the United States. Our sample is drawn solely from California, arguably implying higher values for the volatility parameter.
} 
exercise. Each panel displays the solutions for parameters of interest under a particular specification of $\sigma, k_{b}$ and $k_{l}$. The rows of the table show the values of LTV, the yield, the recovery rate and the default point under various specifications of $\sigma, k_{b}$ and $k_{l}$. The columns are associated with values of $c$ (not shown) that increase moving toward the right; as noted, in each panel we will focus on the value of $c$ that produces the LTV closest to $95 \%$ (indicated in boldface).

The first project is to determine whether one can produce an empirically accurate model under $k_{b}=k_{l}=0$. Panel 1 shows that the spread on a $97 \%$ mortgage is 121 basis points, the recovery rate is $91 \%$ and the default point is $89 \%$. These values are all much higher than we see in the data, so this specification must be rejected.

A lower value of $\sigma$ would be expected to render default less probable (at least under the assumption that the effect of reducing $\sigma$ on the default point is minor). Panel 2 shows that the effect of reducing volatility to $\sigma=10 \%$ is to produce a spread of 36 basis points on a $95 \%$ mortgage, approximately equaling that seen in the data. However, the effects of specifying the lower value of $\sigma$ on the default point and the recovery rate are minor, implying that the predicted values for these variables remain much higher than the values we are looking for. We conclude that, despite the simplification that would result from excluding default costs, doing so does not produce a satisfactory calibration.

We have seen that when borrowers incur costs upon default, the spread-LTV relation becomes flatter; for given LTV, default costs decrease the default point and decrease the effects of the default option on the spread. Such a change would be expected to move the model predictions in the direction of the data. Panel 3 shows $\sigma=15 \%, k_{b}=4, k_{l}=0$. Making this change reduces the spread on a $92 \%$ mortgage to 60 basis points, only slightly higher than what we see in the data. The recovery rate and default point are $71 \%$ and $65 \%$, which are also close to the values we seek.

One could make a case for an even higher value for $k_{b}$; if $k_{b}=8$, so that default costs equal $32 \%$ of the purchase price of a house, then the yield spread on a $94 \%$ loan is 38 basis points, the recovery rate is $56 \%$ and the default point is $53 \%{ }^{16}$

On prior grounds it is unclear whether borrowers' default costs are positive or negative. How-

\footnotetext{
${ }^{16}$ In Panel 4, under the assumed parameter values borrowers never default when $c=.5$.
} 
Table 3: Model-calibrated yields and LTV

(1) $\sigma=15 \%, k_{b}=k_{l}=0$

\begin{tabular}{lccccccc}
\hline c & 0.5 & 0.75 & 1.00 & 1.25 & 1.50 & 1.75 & 2.00 \\
LTV(\%) & 28.54 & 42.65 & 56.38 & 69.36 & 81.04 & 90.69 & $\mathbf{9 7 . 4 0}$ \\
Yield(\%) & 7.01 & 7.04 & 7.10 & 7.21 & 7.40 & 7.72 & $\mathbf{8 . 2 1}$ \\
Recovery(\%) & 77.69 & 77.98 & 78.65 & 79.91 & 82.07 & 85.56 & $\mathbf{9 1 . 0 5}$ \\
Default point & 0.22 & 0.33 & 0.44 & 0.55 & 0.67 & 0.78 & $\mathbf{0 . 8 9}$
\end{tabular}

(2) $\sigma=10 \%, k_{b}=k_{l}=0$

$\begin{array}{lccccccc}\text { c } & 0.5 & 0.75 & 1.00 & 1.25 & 1.50 & 1.75 & 2.00 \\ \operatorname{LTV}(\%) & 28.57 & 42.85 & 57.09 & 71.10 & 84.28 & \mathbf{9 5 . 0 9} & 100.00 \\ \text { Yield(\%) } & 7.00 & 7.00 & 7.01 & 7.03 & 7.12 & \mathbf{7 . 3 6} & 8.00 \\ \text { Recovery(\%) } & 87.50 & 87.51 & 87.59 & 87.91 & 88.99 & \mathbf{9 2 . 0 2} & 100.00 \\ \text { Default point } & 0.25 & 0.38 & 0.50 & 0.63 & 0.75 & \mathbf{0 . 8 8} & 1.00\end{array}$

(3) $\sigma=15 \%, k_{b}=4, k_{l}=0$

\begin{tabular}{lccccccc}
\hline $\mathrm{c}$ & 0.5 & 0.75 & 1.00 & 1.25 & 1.50 & 1.75 & 2.00 \\
LTV(\%) & 28.57 & 42.76 & 56.66 & 69.90 & 81.95 & $\mathbf{9 2 . 0 9}$ & 99.41 \\
Yield(\%) & 7.00 & 7.02 & 7.06 & 7.15 & 7.32 & $\mathbf{7 . 6 0}$ & 8.05 \\
Recovery(\%) & 34.15 & 48.74 & 56.35 & 61.53 & 66.01 & $\mathbf{7 0 . 7 8}$ & 76.72 \\
Default point & 0.10 & 0.21 & 0.32 & 0.43 & 0.54 & $\mathbf{0 . 6 5}$ & 0.76
\end{tabular}

(4) $\sigma=15 \%, k_{b}=8, k_{l}=0$

\begin{tabular}{lccccccc}
\hline $\mathrm{c}$ & 0.5 & 0.75 & 1.00 & 1.25 & 1.50 & 1.75 & 2.00 \\
$\operatorname{LTV}(\%)$ &. & 42.85 & 57.01 & 70.75 & 83.59 & $\mathbf{9 4 . 8 4}$ & 103.62 \\
Yield(\%) &. & 7.00 & 7.02 & 7.07 & 7.18 & $\mathbf{7 . 3 8}$ & 7.72 \\
Recovery(\%) &. & 19.66 & 34.22 & 43.24 & 49.86 & $\mathbf{5 5 . 6 4}$ & 61.62 \\
Default point &. & 0.08 & 0.20 & 0.31 & 0.42 & $\mathbf{0 . 5 3}$ & 0.64
\end{tabular}

(5) $\sigma=15 \%, k_{b}=0, k_{l}=4$

\begin{tabular}{lccccccc}
\hline c & 0.5 & 0.75 & 1.00 & 1.25 & 1.50 & 1.75 & 2.00 \\
LTV(\%) & 28.45 & 42.29 & 55.42 & 67.28 & 77.14 & 84.05 & $\mathbf{8 6 . 8 4}$ \\
Yield(\%) & 7.03 & 7.09 & 7.22 & 7.43 & 7.78 & 8.33 & $\mathbf{9 . 2 1}$ \\
Recovery(\%) & 21.69 & 40.80 & 51.14 & 58.60 & 65.48 & 73.29 & $\mathbf{8 3 . 6 9}$ \\
Default point & 0.22 & 0.33 & 0.44 & 0.55 & 0.67 & 0.78 & $\mathbf{0 . 8 9}$
\end{tabular}

(6) $\sigma=15 \%, k_{b}=4, k_{l}=4$

\begin{tabular}{lccccccc}
\hline $\mathrm{c}$ & 0.5 & 0.75 & 1.00 & 1.25 & 1.50 & 1.75 & 2.00 \\
$\mathrm{LTV}(\%)$ & 28.56 & 42.69 & 56.35 & 69.04 & 80.04 & 88.46 & $\mathbf{9 3 . 1 5}$ \\
Yield(\%) & 7.00 & 7.03 & 7.10 & 7.24 & 7.50 & 7.91 & $\mathbf{8 . 5 9}$ \\
Recovery(\%) & -21.87 & 11.34 & 28.26 & 39.12 & 47.59 & 55.60 & $\mathbf{6 4 . 7 0}$ \\
Default point & 0.10 & 0.21 & 0.32 & 0.43 & 0.54 & 0.65 & $\mathbf{0 . 7 6}$
\end{tabular}

(7) $\sigma=10 \%, k_{b}=4, k_{l}=4$

\begin{tabular}{lccccccc}
\hline c & 0.5 & 0.75 & 1.00 & 1.25 & 1.50 & 1.75 & 2.00 \\
LTV $(\%)$ & 28.57 & 42.86 & 57.11 & 71.18 & 84.44 & $\mathbf{9 5 . 0 8}$ & 98.88 \\
Yield(\%) & 7.00 & 7.00 & 7.00 & 7.02 & 7.12 & $\mathbf{7 . 3 6}$ & 8.10 \\
Recovery(\%) & -17.50 & 17.50 & 35.02 & 45.66 & 53.30 & $\mathbf{6 0 . 4 8}$ & 70.80 \\
Default point & 0.11 & 0.24 & 0.36 & 0.49 & 0.61 & $\mathbf{0 . 7 4}$ & 0.86
\end{tabular}


ever, there is not much doubt that lenders' default costs are positive and high. Therefore we might want to impose $k_{l}>0$ on any candidate set of parameter values. However, we have already seen that introducing lenders' costs increases the curvature of the spread-LTV curve, so setting $k_{l}>0$ together with $k_{b}=0$ is not likely to produce an accurate calibration. Indeed, as Panel 5 shows, under these parameter values the model cannot produce LTV anywhere near $95 \%$ for any value of c. For LTV $=87 \%$ default occurs at an unrealistically high value of $x_{*}\left(x_{*}=.89\right)$, and lenders would require a spread of 221 basis points to compensate them for expected default costs. These values are a long way from those seen in the data.

It follows from this that $k_{l}>0$ cannot produce an accurate calibration in conjunction with $k_{b}=0$, but this is not necessarily the case if $k_{b}$ is also strictly positive. Borrowers' default costs decrease the default point, therefore attenuating the effect of default on LTV (for given $c$ ) and the spread. In Panel 6 we show $\sigma=15 \%, k_{b}=k_{l}=4$. Under these values the lender is willing to fund a $93 \%$ loan, but only under a spread of 159 basis points, which again is much higher than in the data. The recovery rate is $65 \%$ and the default point is $76 \%$, which are also probably too high.

In Panel 7 we continue to assume $k_{b}=k_{l}=4$, but set $\sigma$ equal to $10 \%$. On a $95 \%$ loan this specification produces a spread of 36 basis points, a recovery rate of $60 \%$ and a default point of $74 \%$. All of these values are plausible, although as noted the specification $\sigma=10 \%$ is itself probably too low.

In sum, we conclude that Panels $3\left(\sigma=15 \%, k_{b}=4, k_{l}=0\right)$ and $7\left(\sigma=.1, k_{b}=4, k_{l}=4\right)$ produce the best results. The specification of Panel 3 has the drawback that it unrealistically sets lender costs at zero, while the Panel 7 run specifies a value of $\sigma$ that is probably unrealistically low.

\section{Conclusions}

In the introduction we observed that the high mortgage default rates of the past several years, together with the resulting huge losses to holders of mortgages, could reflect either drastic mispricing of mortgages or extreme realizations of shocks. We assumed initially that it would not be difficult to find evidence that mispricing is the major culprit. However, that has not been the case: we are able to calibrate a model of optimal mortgage default and mortgage pricing that has reasonable success 
in reproducing the patterns in the data. Assuming Wall Street firms were using models similar to that presented here (granted, it is not clear that this was the case), it follows that mispricing is of secondary importance relative to extreme realizations of house price shocks. Of course, with hindsight it is easy to criticize lenders and borrowers for not predicting that the housing price bubble would eventually be reversed, and acting accordingly. Our point is only that models that rule out foresight of house price changes - a realistic specification, in our opinion - can be calibrated to the data with fair success.

Let us be a bit more specific about the successes and failures of our modeling exercise. Most obviously, the model here does not predict the event of default with anything like complete accuracy. As noted, the model predicts that all the mortgages with a given LTV initiated at a given date will all default at the same time if any of them defaults. In fact there is wide variation in the default points. This variation reflects the importance of life events in motivating default. The assumption here that borrowers can always buy back their mortgages at prices equal to economic values had the effect of shutting down his line of causation. It should not be surprising that considerable loss of explanatory power results.

The qualitative predictions of the model for default and pricing turn out to be largely substantiated in the data. High-LTV mortgages are more prone to default than low-LTV mortgages, as the model (or common sense) predicts. Further, the dependence of mortgage pricing on LTV conforms to the prediction of the model (more precisely, we can find parameter values for which this is the case).

One striking finding is that for FRMs the effect of LTV on yield spreads appears to be separable from the other risk factors; specifically, the difference between the yields on two otherwise identical mortgages with different LTV is the same whether or not one corrects for risk factors other than LTV. The interpretation is that the effect of LTV on expected default does not interact to a major extent with other risk factors. Having this result greatly simplifies the analysis of the effect of LTV on default and mortgage pricing.

Two other caveats made in the text above bear repeating here. First, the equilibrium depends on parameters like default costs that are extremely difficult to measure directly. As a result of our 
inability to calibrate these parameters credibly, we take the view that model is not readily testable. Second, we noted that our data set does not allow us to link first- and second-lien mortgages, making it difficult to measure LTVs on $80 \%$ mortgages. We proceeded despite this problem, but there is no denying its importance.

One of the most important empirical conclusions stated above is that FRMs and ARMs display very different behavior: high-LTV ARMs are much more prone to default than FRMs with the same LTV. Further, this dramatic difference in default behavior is reflected in pricing in exactly the way the model predicts: the yield premium on high-LTV ARMs appears to be much larger than the yield premium for otherwise similar FRMs. This difference reflects the fact that ARMs are easier to qualify for than FRMs, implying that highly qualified borrowers make greater use of FRMs and less-qualified borrowers specialize in ARMs. This observation, while correct, leaves open the question why lenders set the standards for qualification so differently in the two cases.

\section{References}

Case, K. E., And R. J. Shiller (1989): "The Efficiency of the Market for Single Family Homes," American Economic Review, 79(1), 125-137.

Coleman, M. D., M. LaCour-Little, and K. D. Vandell (2008): "Subprime Lending and the Housing Bubble: Tail Wags Dog?," working paper.

Demyanyk, Y. S., And O. van Hemert (2008): "Understanding the Subprime Mortgage Crisis," forthcoming in the Review of Financial Studies.

Deng, Y., J. M. Quigley, and R. VanOrder (2000): "Mortgage Terminations, Heterogeneity and the Exercise of Mortgage Options," Econometrica, 2, 275-307.

Dixit, A. K., And R. S. Pindyck (1994): Investment Under Uncertainty. Princeton University Press.

Doms, M., F. Furlong, And J. Krainer (2008): "Subprime Mortgage Delinquency Rates," Federal Reserve Bank of San Francisco working paper. 
Downing, C., R. Stanton, and N. Wallace (2005): "An Empirical Test of a Two-Factor Mortgage Valuation Model: How Much Do House Prices Matter?," Real Estate Economics, 29, 449-470.

Flavin, M., and T. Yamashita (2002): "Owner-Occupied Housing and the Composition of the Household Portfolio," American Economic Review, 92(1), 345-362.

Gerardi, K., A. H. Shapiro, and P. S. Willen (2008): "Subprime Outcomes: Risky Mortgages, Homeownership Experiences, and Foreclosures," working paper.

Gerardi, K. S., A. Lehnert, S. M. Sherlund, and P. S. Willen (2009): "Making Sense of the Subprime Crisis," .

Kau, J. B., And D. C. Keenan (1995): "An Overview of Option-Theoretic Pricing of Mortgages," Journal of Housing Research, 6, 217-244.

Mayer, C., K. Pence, And S. Sherlund (2008): "The Rise in Mortgage Defaults," forthcoming in the Journal of Economic Perspectives.

Merton, R. C. (1974): "On the Pricing of Corporate Debt: The Risk Structure of Interest Rates," Journal of Finance, 29, 449-470.

Mian, A. R., And A. Sufi (2009): "The Consequences of Mortgage Credit Expansion: Evidence from the U.S. Mortgage Default Crisis," Quarterly Journal of Economics, 124(4). 